\title{
Age and sex differences in everyday problem-solving goals and strategies for work and caregiving vignettes
}

Jennifer A. Flinn

West Virginia University

Follow this and additional works at: https://researchrepository.wvu.edu/etd

\section{Recommended Citation}

Flinn, Jennifer A., "Age and sex differences in everyday problem-solving goals and strategies for work and caregiving vignettes" (2007). Graduate Theses, Dissertations, and Problem Reports. 4301.

https://researchrepository.wvu.edu/etd/4301

This Dissertation is protected by copyright and/or related rights. It has been brought to you by the The Research Repository @ WVU with permission from the rights-holder(s). You are free to use this Dissertation in any way that is permitted by the copyright and related rights legislation that applies to your use. For other uses you must obtain permission from the rights-holder(s) directly, unless additional rights are indicated by a Creative Commons license in the record and/ or on the work itself. This Dissertation has been accepted for inclusion in WVU Graduate Theses, Dissertations, and Problem Reports collection by an authorized administrator of The Research Repository @ WVU.

For more information, please contact researchrepository@mail.wvu.edu. 
Age and Sex Differences in Everyday Problem-Solving Goals and Strategies for Work and Caregiving Vignettes

Jennifer A. Flinn

\author{
Dissertation submitted to the \\ Eberly College of Arts and Sciences \\ at West Virginia University \\ in partial fulfillment of the requirements \\ for the degree of \\ Doctor of Philosophy \\ in \\ Psychology \\ JoNell Strough, Ph.D., Chair \\ Mary Carter, Ph.D. \\ Stanley Cohen, Ph.D. \\ Barry Edelstein, Ph.D. \\ Julie Patrick, Ph.D. \\ Department of Psychology
}

Morgantown, West Virginia

2007

Keywords: Problem Solving, Age Differences, Sex Differences, Goals, Strategies

Copyright 2007 Jennifer A. Flinn 


\begin{abstract}
Age and Sex Differences in Everyday Problem-Solving Goals and Strategies for Work and Caregiving Vignettes
\end{abstract}

Jennifer A. Flinn

The current study examined how age and sex of participants, gender stereotype roles for the protagonist, and domain of the problem influenced the generation of problem-solving goals and strategies. One hundred and seventeen participants, 136 younger adults $(M=$ $19.22, S D=1.30: 58 \mathrm{M}, 78 \mathrm{~F})$ and 81 older adults $(M=73.17, S D=7.76: 38 \mathrm{M}, 43 \mathrm{~F})$ were given two hypothetical vignettes, one in the work domain, and one in the caregiving domain. Responses were coded for other-focused goals and interpersonally-oriented strategies. A 2 (age) x 2 (sex) x 2 (form type) x 2 (domain) MANOVA indicated two significant three-way interactions for interpersonally-oriented strategies: domain by strategy by sex and strategy by age by sex. Results indicated that the reporting of discussion strategies varied by domain, Wilks' $\Lambda=.806, F(1,212)=51.10, p<.001$, and for the work domain, men were more likely to report seeking support strategies than women, $F(1,212)=9.21, p<.003, \eta^{2}=.04$. When collapsed across domain, the only significant result indicated that older men were more likely to report discussion strategies than younger men, $t(92)=-3.59, p<.001$. Finally, only domain differences emerged for other focused goals, Wilks' $\Lambda=.941, F(1,202)=12.75, p<.001$. Results indicate some age and sex differences in strategies, primarily by domain, however other-focused goals did not serve as a mediator of these differences. Implications for understanding the problem solving research methodology (i.e., self-generated problems vs. fixed problems) are discussed. 


\section{Dedication}

I would like to dedicate this dissertation to my mother Carolyn. She was the one who sparked my interest in psychology and then encouraged and supported me through many years of undergraduate and graduate work. Although she was not able to see the completion of this journey, I know she would be proud.

I would also like to thank my father Bill and my brother Jason for their love, support, and patience throughout the process of completing this dissertation. I love you both! 


\section{Acknowledgements}

I would like to thank my advisor and committee chair, Dr. JoNell Strough, for all of her support, encouragement, and advice during the process of writing this dissertation. I would also like to thank my committee members, Dr. Stanley Cohen, Dr. Mary Carter, Dr. Barry Edelstein, and Dr. Julie Hicks Patrick for their time and their valuable suggestions. I also want to thank Sarah Stahl and Cory-Ann Smarr for their assistance with the coding process and for being so generous with their time. Finally, I would like to thank Kelly Schuller, Loriann Sonntag, Jenny Hartley, and Clare Mehta for their support and encouragement over the past few years as I worked on this project. My thanks to all of you.

This study was funded through the Alumni Fund grant provided through the West Virginia Department of Psychology. 
Table of Contents

$\begin{array}{ll}\text { Abstract } & \text { ii }\end{array}$

Chapter 1: Introduction 1

The Problem-Solving Process 2

Problem Solving Strategies 3

Problem Definition and Strategies $\quad 4$

Fixed Vignettes vs. Self Generated Vignettes $\quad 5$

Other-focused or Self-focused Goals and Interpersonally-Oriented 7

Strategies

$\begin{array}{ll}\text { Sex differences in goals } & 8\end{array}$

$\begin{array}{ll}\text { Age differences in goals } & 8\end{array}$

Sex differences in strategies $\quad 9$

$\begin{array}{ll}\text { Age differences in strategies } & 10\end{array}$

Classification of goals and strategies in the current study 10

Domain and Gender Stereotyped Roles as Contextual Variables 11

Domain $\quad 11$

$\begin{array}{ll}\text { Protagonist sex and gender stereotyped roles } & 13\end{array}$

$\begin{array}{ll}\text { Statement of the Problem } & 15\end{array}$

$\begin{array}{ll}\text { Research Questions and Hypotheses } & 15\end{array}$

$\begin{array}{ll}\text { Chapter 2: Methods } & 18\end{array}$

$\begin{array}{lr}\text { Participants } & 18\end{array}$

$\begin{array}{ll}\text { Measures } & 19\end{array}$

Demographic information $\quad 19$ 
$\begin{array}{ll}\text { Problem vignettes } & 20\end{array}$

Domains for the problem vignette $\quad 20$

$\begin{array}{ll}\text { Sex of the protagonist in the problem vignettes } & 21\end{array}$

Pilot testing of the problem vignettes $\quad 21$

$\begin{array}{ll}\text { Strategies } & 22\end{array}$

$\begin{array}{ll}\text { Strategy Coding } & 22\end{array}$

$\begin{array}{ll}\text { Goals } & 25\end{array}$

$\begin{array}{ll}\text { Goal Coding } & 25\end{array}$

$\begin{array}{ll}\text { Procedure } & 27\end{array}$

$\begin{array}{ll}\text { Chapter 3: Results } & 28\end{array}$

$\begin{array}{ll}\text { Design and Variables } & 28\end{array}$

$\begin{array}{ll}\text { Missing Data } & 29\end{array}$

$\begin{array}{lr}\text { Selection of Strategies for Analysis } & 29\end{array}$

$\begin{array}{ll}\text { Normality of Data and Outliers } & 30\end{array}$

Strategies for the Work and Caregiving Problems 31

Discussion strategy by domain x sex $\quad 32$

Seeking support strategy by domain x sex $\quad 33$

Discussion strategy by age and sex 33

Seeking support strategy by age and sex $\quad 34$

Goals for the Work and Caregiving Problems 34

Testing the Mediation Model 34

Additional Analyses - Instrumentally-Oriented Strategies 36

Deliberation strategy by domain x sex $\quad 37$ 
Figure 1. Model for everyday problem solving (adapted from Sansone \& Berg, 1993)

Figure 2. Mediation model: goals as mediators of problem-solving strategies 
Figure 3. Chart for domain by strategy by sex interaction

Figure 4. Chart for strategy by age by sex interaction

Table 1. Demographic Information: Sex, Race, and Religious Affiliation

Experience with Caregiving

Table 3. Demographic Information: Education, Income, and Marital Status

Table 4. Distribution of Form Type for Returned Questionnaires by Age and Sex

Table 5. Analysis of Variance Results for Seeking Support by Domain by Sex

Table 6. Means and Standard Deviations for Seeking Support Proportion Scores for the Work Problem by Age

Table 7. Analysis of Variance Results for Main Effects and Interaction Effects of Age and Sex on Collapsed Discussion Proportion Scores

Table 8. Means and Standard Deviations for Collapsed Discussion Proportion Scores by Age and Sex

Table 9. Correlations Between Other- and Self-Focused Goals and 
The purpose of this study is to examine the role that goals play in problem solving, specifically how individual factors (such as age and $\operatorname{sex}^{1}$ ) and contextual factors (such as the sex of the protagonist in the problem and the domain in which the problems occurs) may affect goals, whether goals are related to problem-solving strategies, and if goals function as mediators of strategy differences. In everyday problem solving, problems are likely to occur within a complex social context in which multiple issues and concerns are prominent, various solutions are possible, and the consideration of others in the problem is an important issue (Berg \& Calderone, 1994, Berg \& Klacyznski, 1996; Denney \& Pearce, 1989). Much of the research in the area of everyday problem solving has focused on solutions or strategies for problem solving. (Blanchard-Field, Chen, \& Norris, 1997; Blanchard-Field, Mienaltowski \& Seay, 2007; Cornelius \& Caspi, 1987; Diehl, Coyle, \& Labouvie-Vief, 1996; Walker, Irving, \& Berthelson, 2002; Watson \& Blanchard-Fields 1998). Another aspect of the problem-solving process that has been addressed is

${ }^{1}$ In the problem-solving literature, researchers use the terms "sex" and "gender" somewhat interchangeably to refer to men and women. Some researchers opt to use the term sex differences (e.g., Diehl, Coyle, Labouvie-Vief, 1996) in describing their results, while many other researchers use the term gender difference (e.g., D’Zurilla, Nezu, \& Maydeu-Olivares, 1998; Rubin \& Krasnor, 1983; Strough \& Berg, 2000) to describe any differences between men and women. The difficulty of distinguishing what differences are due to biology ("sex") or due to social and cultural learning ("gender") may possibly account for researchers selecting only one term to describe all of these factors. The current study will primarily use the term sex rather than the term gender to describe differences between men and women. 
individuals' goals. Goals have been examined as a way to assess how individuals define problems and as a means of understanding the strategies individuals use to solve problems (Berg \& Calderone, 1994; Berg, Strough, Calderone, Sansone, \& Weir, 1998; Sansone \& Berg, 1993). Individuals' strategies for solving problems might be generated based on what goal the individual is trying to accomplish or attain.

In real world scenarios, different individuals may look at the same problem and determine very different goals as being important. As a result, this may affect the solutions that individuals think of to address the problem. Although goals have been examined in problem-solving studies (e.g., Berg et al., 1998), this research is somewhat limited. Additionally, research examining age and sex differences in everyday problemsolving strategies and goals (Berg et al., 1998; Strough, Berg, \& Sansone, 1996) has been based on self-generated problems provided by participants. These responses can vary greatly in content and focus and make it difficult to determine if differences in the problem-solving process are the result of age and sex differences or the types of problems participants are generating. Rather than using participant-generated problems the current study presented all participants with identical problems. This study then examined whether age and sex differences in strategies and goals would be observed when participants responded to the same researcher-generated problems. Additionally, the study considered whether problem-solving goals and strategies would be associated, and if goals would mediate any differences observed in problem-solving strategies.

\section{The Problem-Solving Process}

The process of problem solving has been described by many different researchers in numerous fields of study including stress and coping, aggression research, stereotypes 
of intelligence, and social problem solving (e.g., Diehl, 1996; Labouvie-Vief, HakimLarson, \& Hobart, 1987; Keltikangas-Järvinen, 1997; Quinn \& Spencer, 2001; Walker, Irving, \& Berthelson, 2002), but the steps in the process are similar across these descriptions. The steps of the process involve defining the problem and goal setting, followed by generation, evaluation, and selection of effective solutions, and finally implementation of the chosen solution and evaluation of the results (e.g., Crick \& Dodge, 1994; McMurran, Fyffe, McCarthy, Duggan, \& Latham, 2001). D'Zurilla and colleagues (2004, p. 12) define problem solving as “...the self directed cognitive-behavioral process by which an individual, couple, or group attempts to identify or discover effective solutions for specific problems encountered in everyday living". They go on to discuss the differences between demands presented in problems, and mention that interpersonal problems are special because the focus of such problems are "... aimed at identifying or discovering a resolution to the conflict that is acceptable or satisfactory to all parties involved" (D'Zurilla et al., 2004, p. 13). Interpersonal problems can incorporate issues involving multiple individuals, conflicting purposes, unclear resolutions, and other demands. Two interpersonal problems will be used in the present study. Problem Solving Strategies.

Strategies are the specific plans, methods, or means of achieving a solution to a problem (e.g. Berg \& Klaczynski, 1996; Blanchard-Fields, Jahnke, \& Camp, 1995). Researchers often focus on strategies as outcomes of the problem-solving process, although other outcome measures are possible, such as performance and whether the problem is successfully solved (e.g. Chrysikou, 2006; Seijts \& Latham, 2000). Generation and evaluation of strategies is often studied as a way to assess problem- 
solving ability and is often studied within the adult development and aging literature (Cornelius \& Caspi, 1989; Denney \& Pearce, 1987; Crawford \& Channon, 2002). Thus in the current study, participants' strategies will be examined.

The strategies individuals select to solve a problem are thought to reflect their definitions of the problem and previous research has found evidence of such associations (Berg \& Calderone, 1994; Blanchard-Fields, Chen, \& Norris, 1997; Blanchard-Fields et al., 2007; Sansone \& Berg, 1993). Problem definition, or interpretation, encompasses the idea that each individual will understand and define problems in different ways. Participants are likely to interpret problems in a manner differing from other participants and even from researchers' expectations as to what is important in the problem (Berg \& Calderone, 1994; Berg et al., 1998). Problem definitions reflect individuals' own unique experience with the problem, which may or may not include or emphasize aspects seen as important to another observer (Berg et al., 1998). One method of assessing problem definition is to examine the goals that participants generate for a problem (Berg et al., 1998). Goals can be defined as objectives for solving a problem or the purpose towards which solutions are directed (e.g. Berg et al, 1998; Berg \& Calderone, 1994; Strough et al., 1996). Goals may also allow insight into an individuals' cognitive evaluation of the primary issues in a problem-solving process (Berg et al., 1998). The current study examined problem definition by means of the goals that individuals report for two problem situations.

\section{Problem Definition and Strategies}

The influence of problem definitions generated by individuals for problem solving vignettes and the strategies that are subsequently generated for those problems has been 
addressed in previous research. Blanchard-Fields and colleagues' (1995) research suggests that age group differences in problem-solving responses are based, in part, on how individuals understand the problem situation. Berg and Calderone (1994) observed that students in their study found problem-solving strategies matching their interpretations, whether task-oriented or interpersonal, to be more effective than strategies that did not match their interpretations. Finally, Berg and colleagues' (1998) research showed that participants who included interpersonal/social aspects in their goals were more likely to report strategies that involved social aspects (such as including others in the solution), while those with competence/achievement aspects in their goals were more likely to report self-oriented strategies.

These results indicate a relation between individuals' problem goals, and the strategies that they subsequently select. Taking these results to the next step, it might be the case that participants' goals were functioning as mediators of the differences in participants' strategies. At least one study (Strough et al., 1996) found that sex differences in other-focused goals were diminished when the problem definition included other people as central to the problem. To examine this issue, the current study specifically addressed whether goals may serve as mediators of age and sex differences in strategies for the problem-solving process or if other factors (such as age and sex) would account for differences above and beyond what goals predicted.

\section{Fixed Vignettes vs. Self Generated Vignettes}

Previous studies examining differences in problem-solving goals and strategies have relied on self-generated problems provided by the participants in the study (Berg et al., 1998; Strough et al., 1996). Although this method has many benefits, it does bring 
into question whether the age and sex differences observed in these studies were somewhat dependent on the type of problems participants chose to address. For example, results might indicate that women are more likely to report goals and strategies reflecting interpersonal concerns, but it could be that women are simply more likely to recall and report problems involving other people and interpersonal issues than men. Strough and colleagues (1996) acknowledge that the relationship between women and interpersonal problems and goals might actually be influenced by female participants encountering interpersonal problems more often, or at recalling these types of problems at a greater frequency than male participants. In presenting participants with the same problem situations, the current study attempted to lessen the possible effect of these factors on problem vignettes.

Another important difference between the current study and more recent work by Blanchard-Fields and colleagues (2007) is that participants were asked to provide openended responses to the problem vignettes in the current study. In other words, all participants in this study had to answer questions regarding the same two vignettes, but they were not limited in the responses they could give to the problem. Blanchard-Fields and colleagues' study only provided participants with four strategy responses for each vignette. Although this allowed strategy responses to be easily categorized, it limited the responses that participants could provide for the situation. In the present study, participants were encouraged to write down all of the possible strategies they could think of for each problem, with no limits on the response. Likewise, the question regarding goals for the problem vignettes was an open-ended response, so participants' responses were not limited in content or length. 


\section{Other-focused or Self-focused Goals and Interpersonally-Oriented Strategies}

Following the work of Richards (1966), many researchers have examined the concept of life goals, which include the overall objectives individuals have for their lives, such as goals for relationships, career advancement, personal happiness, and other's needs (Hakim, 2006; Roberts, O'Donnell, \& Robins, 2004). Although participants' life goals are of importance in their approach to everyday problems, the current study only focused on the specific goals that participants generated for the problem vignettes presented in the questionnaire.

When specifying goals and strategies for problems, individuals may focus on issues involving self-interest concerns, such as independence and individual achievement, or the concerns of other people and roles within a group (Berg et al., 1998; Strough et al., 1996). Bakan (1966) conceptualized this difference as being between the individual alone (agency) and the individual as part of a larger group (communion). Agentic qualities are consistent with stereotypical masculine gender roles and involve being active, decisive, aggressive, dominant, and reflect concern with independence or concern for the needs of self, (Abele, 2003; Bakan, 1966; Moskowitz, Suh \& Desaulniers, 1994; Strough et al., 1996). Communal qualities are consistent with feminine gender roles and include being emotional, caring, supportive, agreeable, and reflect a higher level of concern with interdependence or concern for the needs of others (Abele, 2003; Bakan, 1966; Moskowitz et al., 1994; Strough et al., 1996). The current study will specifically focus on the use of other-focused or self-focused considerations in participants' goals and interpersonally-oriented or individually-oriented strategies. 
Sex differences in goals. A number of studies suggest that women are more likely to self-identify with qualities typically considered to be interpersonal and other-focused, while men use more instrumental, self-focused descriptors (Abele, 2003; Diehl, Owen, \& Youngblade, 2004; Gilligan, 1982). When examining individual reports of their own everyday problem solving, Strough and colleagues (1996) found that women were more likely than men to describe problems where other people were central to the problem itself and to report goals that concerned desired outcomes for other people. However, when men reported other people as central to the problem, they too reported otherfocused goals (Strough et al., 1996). This finding may indicate that when men and women are addressing a similar problem, there may be no sex differences in problemsolving goals. In the current study addresses the possibility that sex differences in goals will be nominal when problem situations are identical. All men and women in the study will respond to the same work and caregiving problems, and responses will be examined to see if sex differences in other-focused goals are observed.

Age differences in goals. Age may also be important for understanding other- and self-focused goals and strategies. Previous studies in the problem-solving literature have found age differences that indicate that younger adults display a more self-focused orientation and older adults demonstrate an orientation more focused on other people (Diehl et al., 2004; Strough et al., 1996).

Problem-solving goals may reflect individuals' larger life tasks and roles. For younger adults, independence and self-focused orientation may be developmentally appropriate given the life tasks typically encountered in this time of life, such as excelling in college, beginning a career, and moving out on their own for the first time (Zirkel \& 
Cantor, 1990). As individuals age, life tasks may allow for a shift from an internal, self focus to an external focus that incorporates a greater concern for other people (Nurmi, Pulliainen, \& Salemela-Aro, 1992). Older adults, especially those who have a perception that their remaining time is limited, prefer to focus on emotionally meaningful goals, including other-focused goals more than instrumental goals, including achievement and independence goals (Lang \& Carstensen, 2002). The current study examined whether age differences might exist in the use of self- or other-focused problem goals and strategies. If independence and self-focus are prominent in younger adults and concern for other people is more characteristic of older adults, it was expected that in the present study, older adults would be more likely to report other-focused goals and strategies while younger adults reported goals and strategies more likely to reflect a self focus.

Sex differences in strategies. Some research suggests that men and women differ in the way they approach the problem-solving process (Diehl et al, 1996; D'Zurilla, Maydeu-Olivares, \& Kant, 1998), and some research suggests men and women respond to problems with different strategies. Watson and Blanchard-Fields (1998) found that although other-oriented strategies were preferred over self-oriented strategies overall for a set of hypothetical problems, women were less likely to prefer self-oriented strategies (for problems where conflict was likely), and more likely than men to seek outside assistance. However, sex differences are not always evident in problem-solving research. For some studies, this is because no significant differences in sex were observed in the problem-solving process (Blanchard-Fields et al., 1995). For other problem-solving studies, sex is not a factor that is examined in the design of the study (Berg et al., 1998; Blanchard-Fields et al., 2007). By examining individuals' goals for problem solving in 
the current study, it may be possible to explore problem conditions that are associated with sex differences, or apparent lack of sex differences, in problem-solving strategies.

Age differences in strategies. In previous research examining problem solving and older adults, some studies have suggested that problem-solving performance decreases in later life, as indexed by number of generated strategies and positive problem orientation (Denney \& Pearce, 1989; D’Zurilla et al., 1998), but other studies report evidence to indicate that older adults utilize a larger bank of strategies depending on the nature of the problem (Blanchard-Fields et al., 1995; 1997; 2007). Age differences in strategies for instrumental problems may not vary greatly between younger and older adults or may even show that older adults are more likely to select problem-focused strategies (Blanchard-Fields et al, 1995; 1997; 2007), perhaps because instrumental problems seem to naturally elicit problem focused and action oriented strategy responses. For interpersonal problems, however, differences between younger and older adults can be more evident, with older adults more likely to select a range of strategies, including emotion regulation and avoidance/denial strategies to deal with the problem (BlanchardFields et al., 1997; 2007). Problem vignettes in the current study incorporate both instrumental and interpersonal elements, so age differences were expected in the strategies that participants generated for the study.

Classification of goals and strategies in the current study. Goals in this study were classified as other-focused and/or self-focused and strategies were classified as interpersonally-oriented or individually-oriented. For both problems (work and caregiving) other-focused goals and interpersonally-oriented strategies were characterized by a focus on the needs of other individuals in the problem (other than the 
protagonist). For example, an interpersonally-oriented strategy might focus on a solution that considers the needs of the protagonist's family (i.e. "Joe has to discuss the move with his wife and children"), as would an other-focused goal (i.e. "to make sure her [Rebecca's] family is happy"). Additionally, self-focused goals and individually-oriented strategies were also assessed, and those were characterized by a focus on the needs and desires of the protagonist of the problem. An individually-oriented strategy, for example, might focus on the benefits and costs to the protagonist in the situation (i.e. "Susan should take a trip to Chicago to see if she likes the new office"), and a self-focused goal might be focused on how to deal with the problem in a way that benefits the protagonist (i.e. "to find a way to resolve the problem of his [Michael] mothers care so he doesn't have to leave Boston"). It was expected that individuals who viewed other-focused aspects of the problem as more prominent in problem goals for the protagonist of the vignettes would be more likely to list a higher proportion of interpersonally-oriented strategies in describing what the protagonist should do, while those who primarily considered self-focused aspects in their problem goals would be more likely to report individually-oriented strategies.

\section{Domain and Gender Stereotyped Roles as Contextual Variables}

In addition to individual factors such as age and sex, the context of the problem situation must also be considered in the problem-solving process. Two aspects of the problem considered in the current study are gender stereotyped roles for the protagonist involved in the problem, and the domain in which the problem occurs.

Domain. A number of studies have looked at the importance of context or domain in the selection of problem-solving strategies (Berg, et al, 1998, Berg \& Klacyznski, 
1996, Cornelius \& Caspi, 1987). Researchers who investigate age differences often use the family domain in research because family situations are typically familiar to individuals of all age groups, and it is a context in which interpersonal interactions are salient (Berg \& Calderone, 1994, Berg et al., 1998, Watson \& Blanchard-Field, 1998).

Studies from other areas of research also illustrate the practical importance of understanding problem solving in everyday family life. The ability to solve everyday problems has been associated with positive adjustment to stressful situations, such as caregiving (Elliott \& Shewchuk, 2003), and other caregiving studies have supported the idea that effective coping strategies are important to the mental well-being of caregivers (Gottlieb \& Rooney, 2004; Pruchno \& Kleban, 1995). Problem-solving competence and good problem-solving communication has also been demonstrated as important in maintaining marital satisfaction during the transition to parenthood (Cox et al., 1999). These studies indicate that problem solving is an important aspect of family life, both for interactions in families with children, and for adult children interacting with older parents.

In the current study, everyday problem solving was investigated within the overall domain of family, due to the familiarity most individuals have with family situations. Problems in two specific domains were presented in the questionnaire. One problem dealt with the possibility of a dual-income family relocating because of a work opportunity. In this situation, an individual with a spouse and family residing in Philadelphia is offered a job promotion that would move the family to Chicago. The vignette is based, in part, on similar problems used by Smith and Baltes (1990). The second problem dealt with a couple faced with the caregiving needs of an older parent. In this problem, an individual 
living in Boston with his/her spouse must decide what to do when a stroke leaves the individual's mother, who lives in St. Louis, in need of care. This vignette is a variation of a problem situation used in work by Lawrence, Goodnow, Woods, and Karantzas (2002). These problems were selected because they are believed to be relevant to both age groups (younger and older adults). That is, although it was not expected that every participant would have first-hand experience with the situation from the perspective of the protagonist, the problems were such that participants might have had secondary experience to draw from (i.e. having parents decide to move because of a job; having a parent who is caring for a grandparent). These problems are explained in greater detail in later sections, and are available in Appendix A.

Protagonist sex and gender stereotyped roles. When a problem scenario presents information about other people's problems, features of those other people, such as their sex, are a potentially important aspect of the context that may influence problem interpretations. Studies examining social problem solving in children have found the sex of a protagonist in a vignette to be important in understanding strategies (Rubin \& Krasnor, 1983; Walker et al., 2002). Although these studies deal primarily with children's problem-solving strategies, it is possible that protagonist sex will influence participants' responses in the current study. Furthermore, if participants are presented problems and asked to interpret the situation from the problem-solver's point of view, the sex of the protagonist in the problem may affect the problem-solving process via stereotype activation.

Stereotypes can either address the qualities that a person or group should have (prescriptive stereotypes), or what qualities the person or group already are perceived to 
have (descriptive stereotypes). Burgess and Borgida (1999), for example, found that women can be penalized for being too feminine (descriptive) or for not being feminine enough (prescriptive). They also found women who violated gender stereotypes (e.g. displaying masculine traits) were evaluated more negatively by others. Cooper and Blanchard-Fields (2003) examined gender-related schematic beliefs in adults and found that older adults placed more blame for the problem on women in vignettes that portrayed them in non-traditional schemas, as compared to men in similar vignettes. Another view of stereotype activation is offered by Hoffman and Hurst (1990), and suggests that stereotypes are partially the result of people trying to explain the different percentages of sexes in certain roles by attributing corresponding traits to those individuals. In this view, women would be more likely to be stereotyped as possessing a need to take care of family members than men, as a result of the higher percentage of women who typically fill roles such as family caretakers (Lawrence et al., 2002; Pearlin, Pioli, \& McLaughlin, 2001).

The current study examined whether goals for problem vignettes and subsequent strategies reflected prescriptive stereotypes. Participants were presented with problems in the two different domains described earlier - work and caregiving - in one of two form types. The first form type presented protagonists in gender stereotypical roles - a male protagonist in the work problem and a female protagonist in the caregiving problem. The second form type presented protagonists in non-stereotypical roles - female protagonist for work and male protagonist for caregiving. It was expected that perception of gender roles for each domain, might affect goals and strategies that individuals generated for the different vignettes. 


\section{Statement of the Problem}

Previous research has examined age and sex differences in strategies and goals for problem solving (Berg et al., 1998; Blanchard-Fields et al., 1995; Diehl et al., 1996; Strough, Cheng, \& Swenson, 2002; Thornton \& Dumke, 2005). Research suggests that problem-solving goals and strategies differ systematically on the dimension of self or others focus (Abele, 2003; Moskowitz, et al., 1994; Strough, Berg, \& Sansone, 1996), and goals appear to be related to the types of strategies participants select or report (Berg \& Calderone, 1994; Berg et al., 1998). Additionally, previous problem-solving studies (Berg et al., 1998; Strough et al., 1996) have observed age and sex differences when relying on self-generated problems, which may influence the results for this study. The current study observed whether age and sex difference were still observed when participants received fixed problem vignettes. A final consideration that has not been specifically addressed is whether goals might actually serve to mediate any age and sex differences that are observed in problem-solving strategies. The current study examined whether goals would mediate age and sex differences in problem-solving strategies and possible implications for problem-solving research.

\section{Research Questions and Hypotheses}

Research Question 1: Will interpersonally-oriented strategies for solving hypothetical problems differ by age, sex, form type and domain?

Hypotheses

1) For interpersonally-oriented strategies, it was expected that there would be main effects for age and sex (Berg \& Calderone, 1994, Berg et al., 1998, Blanchard-Fields et al, 1995). Older adults would be more likely to have 
greater proportion scores for interpersonally-oriented strategies (discussion, seeking support) than younger adults (Blanchard-Fields et al, 1995; 2007). Women would be more likely to have greater proportion scores for interpersonally-oriented strategies than men (Berg \& Calderone, 1994). However, it was expected that these main effects would be qualified by the interaction of age and sex. Older adult men would be more likely to have greater proportion scores for interpersonally-oriented strategies than younger adult men. Also, older adult women would be more likely to have greater proportion scores for interpersonally-oriented strategies than older adult men and younger adult men.

2) Based on research regarding prescriptive stereotypes, an interaction of form type and domain was expected (Burgess \& Borgida, 1999; Hoffman \& Hurst, 1990; Lawrence et al., 2002). Participants receiving vignettes with protagonists in stereotypical roles will have greater scores for interpersonallyoriented strategies (discussion, seeking support) for the caregiving domain than participants receiving vignettes with stereotypical roles for the work domain (Lawrence et al., 2002). Participants receiving vignettes with protagonists in non-stereotypical roles will have greater scores for interpersonally-oriented strategies (discussion, seeking support) for the work domain than participants receiving vignettes with non-stereotypical roles for the caregiving domain.

Research Question 2: Will goals for solving hypothetical problems differ by age, sex, form type and domain? 
3) For other-focused goals, it was expected that there would be main effects for age and sex (Berg et al., 1998). Older adults would be more likely to have greater scores for other-focused goals than younger adults. Women were expected to have greater scores for other-focused goals than men.

4) Research regarding stereotypes also suggests main effects for form type and domain (Burgess \& Borgida, 1999; Hoffman \& Hurst, 1990; Lawrence et al., 2002). Participants receiving vignettes with protagonists in stereotypical roles would be more likely to have greater scores for other-focused goals than participants receiving vignettes with protagonists in non-stereotypical roles. The caregiving domain was expected to elicit greater other-focused goal scores than the work domain.

Research Question 3: Will participants' goals predict their reported strategies for the hypothetical problems?

1) Participants with higher other-focused goals would be more likely to have higher interpersonally-oriented strategy proportion scores (Berg et al., 1998; Strough et al, 1996).

Research Question 4: Will goals mediate age, sex, form type, and domain differences in participant's strategies for the hypothetical problems?

1) It was expected that age, sex, form type, and domain differences in interpersonally-oriented strategies for the problem would be mediated by other-focused goals for the problem (Berg et al., 1998; Strough et al, 1996). 


\section{Methods}

\section{Participants}

An existing data set was used for this study. The data set was collected for a master's thesis project (Flinn, 2006). The sample used for the current study consisted of 217 participants, 136 younger adults (58 men and 78 women) and 81 older adults (38 men and 43 women). Younger adults in the sample ranged from 18 to 27 years old ( $M$ $=19.22, S D=1.30)$ and older adults were between 60 and 91 years old $(M=73.17, S D$ =7.76). Age group ranges (younger adults: 18-27; older adults: 60+) in this study are comparable to age group ranges in other related studies (Diehl et al., 2004; Strough et al., 1996; Watson \& Blanchard-Fields, 1998). The sample was primarily White $(97.5 \%$ for older adults, $88.2 \%$ for younger adults), which is representative of the population in the primary geographical area where the data was collected. The majority of participants were from either Pennsylvania or West Virginia; however $25 \%$ of older adults and $23 \%$ of younger adults resided in locations other than those two states.

Nearly half of the older adult participants had bachelor's degrees or higher and reported incomes between $\$ 10,000$ and $\$ 60,000$. Because the younger adult sample consisted primarily of college age students, nearly $98 \%$ of that group had high school as their highest degree earned and reported incomes below $\$ 10,000$. Finally, the majority of younger adults in the sample were not married (91.9\%). In comparison, $70.4 \%$ of older adults indicated that they were currently married, $23.5 \%$ were widowed and $6.2 \%$ were divorced. For a full listing of participants' age, sex, education, incomes, marital status and other demographic information, see Tables 1-3. 
Younger adult participants were recruited from West Virginia University through email announcements and postings in the psychology department. By participating in the study, young adults could earn extra credit for their psychology courses, however, other options for extra credit (i.e. article reviews) were also available. Older adult participants were recruited primarily from the Morgantown and Pittsburgh areas through study advertisements, personal contacts, and visits to senior centers, community centers, and independent-living facilities. Older adults were given the option of being placed in a drawing for a $\$ 100$ gift certificate as a thank you for their participation. Addresses of a random sample of older adults age 60 and older living in West Virginia and Pennsylvania were purchased and were used to recruit participants. Referral of participants (i.e. snowballing) from other participants also was used as a means of recruiting participants. Ultimately, $45 \%$ of distributed packets went to personal contacts and referrals, $39 \%$ to contacts at senior centers and participants from the Friend study (PEPS; Pairs Everyday Problem Solving, Strough, 2006), and 24\% were sent to mailing list names. Of the packets that were returned, $66 \%$ were from personal contacts and referrals, $31 \%$ were from people contacted through senior centers and another study, and 3\% were from individuals on the mailing list (See Table 4).

\section{Measures}

Demographic information. A demographic questionnaire was given to each participant, and included questions regarding age, sex, race, education, residency, income, number and sex of siblings, and number and sex of children. Additionally, the form included question regarding religious affiliation, marital status, living arrangements, occupation, parents' occupation, and spouse's occupation. 
Problem vignette. The problems for this study were presented using vignettes. The use of hypothetical vignettes is a method common to the everyday problem-solving literature (e.g., Blanchard-Fields et al., 1995, 1997; Cornelius \& Caspi, 1987; Denney \& Pearce, 1989). Goals and strategies for the problems were elicited by having participants respond to specific questions (listed below) about the problem faced by the protagonist. The problems presented in each vignette addressed a problem that might occur within a family context.

Domains for the problem vignette. The problems involved the decision to relocate a family due to a job change or a family member requiring caregiving. These vignettes were based on prior studies containing problem-solving situations set in a family context (Lawrence et al., 2002; Smith \& Baltes, 1990). The full text of the two vignettes used in the current study appears in Appendix A.

In one study, Lawrence and colleagues (2002) asked participants to respond to a vignette in which the mother of four adult children had broken her hip and required care for a six-week time period. Participants in their study were then asked to assign caregiving duties to the four children, first based on gender alone, then on factors such as work obligations and having families of their own. Aspects of this vignette (i.e., a mother needed care from an adult child, work and family obligations of the adult child) were incorporated into the caregiving vignette used in the current study. The caregiving vignette for this study described a situation where the protagonist's mother, who lives in St. Louis, suffers a stroke and requires full-time care. The protagonist (either Rebecca or Michael), who lives in Boston with a spouse, must decide what to do in this situation. 
In the other study, Smith and Baltes (1990) presented their participants with four vignettes involving conflicts between work and family. One vignette dealt with a women being offered a promotion at work and deciding whether to take the job at the expense of having children. A second vignette dealt with a man with two children losing his job and considering moving to a new city for employment, even though his wife was currently employed in the current location. Aspects of these two problems (i.e., job promotion, two children, spouse's job, moving to a new city) from Smith and Baltes' work were incorporated into the work vignette used for this study. The work vignette describes a situation where the protagonist (either Joe or Susan) has always lived in Philadelphia but is offered a job promotion in Chicago, and has to consider moving the family to the new location.

Sex of the protagonist in the problem vignettes. There were two forms of the vignettes, one form where the protagonist was a female, and the second form where the problem was identical, but the protagonist was a male. For example, when the protagonist was male in the work vignette, the vignette described a situation where a man named Joe must decide whether or not to take a job in Chicago, even though he has grown up in Philadelphia and his wife Susan and their children have always lived in that city. The alternate form of this question presented the same problem, however Susan became the protagonist of the vignette.

Pilot testing of the problem vignette. The problem vignettes were pilot tested on a small group $(\mathrm{N}=15)$ of adults in the target age groups (younger and older adults) prior to primary data collection. This group was recruited from a local community center and volunteered their services. Pilot testing revealed that the vignettes elicited responses 
sufficient for analysis, specifically that participants wrote answers that were long enough for meaningful analysis and that responses sufficiently answered the questions regarding goals for the problems and strategies addressing the problem. Additionally, the vignettes and pilot responses to the vignettes were examined by a research group comprised of undergraduate and graduate students to determine if there were any issues or questions of concern.

Strategies. Participants were asked to generate strategies for solving the problem by responding to the question "What should Joe (or Susan, Rebecca or Michael) do to deal with the problem? Write down all of the possible ways that Joe (or Susan, Rebecca or Michael) might deal with this problem." Participants were asked to place each strategy response on a separate line on the paper. Participants were not limited in the number of strategies they could list. Participants' responses were transcribed for coding purposes and checked for accuracy.

Strategy Coding. Participants'strategy responses were coded using the Social Problem-Solving Strategy Coding Scheme (Strough, 2007). The Social Problem-Solving Strategy Coding Scheme is based on coding schemes used in other studies to categorize responses to open-ended responses about problem-solving strategies and the categories in the scheme are similar to those used in similar studies (i.e., Berg et al., 1998; BlanchardFields et al., 1995; Patrick \& Strough, 2004). The coding scheme was used in a research study examining problem-solving differences between nominal and friend partner pairs (Strough, 2007). This coding scheme is divided into two general categories and four subcategories for classifying strategies. The first general strategy category, strategies focused on the self, includes the subcategories of thoughts and feelings and action. The 
second general strategy category, strategies focused on other people, includes the subcategories of including other people and influencing other people. Overall, the coding scheme includes sixteen strategy categories, however for the purposes of the current study, four strategy categories were of primary interest.

Specifically, the current study was primarily concerned with four strategy codes: deliberation, self action, discussion, and seeking support. Deliberation involves considering or thinking about a problem, gathering information, deciding and planning (i.e. "Joe should consider the benefits of the new job would provide"). Self action involves any action on the protagonist's part to alter their own behavior or an aspect of the situation or deal with the demands of the problem (i.e. "Rebecca should try to find nursing homes in the St. Louis area"). Discussion involves engaging someone else in the problem and determining their input (i.e. "Susan should discuss the job offer with her husband"). Seeking Support (Seeking Assistance/Social Support) involves asking or pursuing advice, expertise, or additional forms of support and assistance from other individuals in solving the problem (i.e. "Michael could discuss his mother's care with her doctor"). Additionally, twelve other categories were also available for coding purposes (Appendix C).

Strategy scores for each participant included the total number of strategies given for the work problem, total number of strategies given for the caregiving problem, and scores for the number of specific strategies (i.e. 2 deliberation strategies, 3 seeking support strategies, etc.) given for each of the problem vignettes. Strategies scores were then determined based on the number of strategies in each category divided by the total 
number of strategies, yielding proportion scores for each of the four strategy categories. See Appendix C for the strategy coding scheme.

Although the coding process allowed for coding responses into any of the sixteen strategy codes in the scheme, it was expected that most responses would fall into four categories (deliberation, self-action, discuss, seeking support). This was expected based on other problem-solving studies have focused on similar categories when examining strategies (i.e. Berg et al., 1998; Patrick \& Strough, 2004). The possibility of including of additional strategy categories in the final analysis was to be considered if more than $20 \%$ of coded responses fell into any of those categories, however, no other strategies reached the $20 \%$ threshold.

Coding of strategies was conducted by the primary researcher and a graduate research assistant. A subset of data from an unrelated everyday problem solving study (Patrick, 2007) was used to train coders. Over a two week time period, coders reviewed strategies generated for an everyday problem vignette $(\mathrm{N}=145)$, coding the strategies using the coding scheme, discussed the coding scheme and any problems with the scheme, and resolved conflicts. After $80 \%$ overall agreement was reached on the training data, and Kappa values confirmed that coding was reliable for the individual categories, $20 \%$ of the data $(\mathrm{N}=44)$ from the current study was randomly selected to be used for reliability coding. Random selection was accomplished using a random number generator (www.random.org) to select case numbers used for coding. Coders were blind to the age and sex of participants and were instructed not to consult participants' goal responses in determining strategy coding. 
Kappa coefficients were used to assess rater agreement (indicating that agreement on coding was greater than chance). The criterion for Kappa values for the four strategy codes of primary interest was .70 or above. Reliability coding took three weeks, and at the end of the reliability coding the Kappa value for deliberation strategies was .77, for self action strategies the value was .82, for discussion strategies the value was .93 , and for seeking support strategies the value was .87. After achieving this, the primary researcher began to code independently. For the independently coded data, a reliability check for coding was conducted on $5 \%(\mathrm{~N}=8)$ of the coded data. This occurred one week after reliability coding was completed and showed that the two coders were still reliable (deliberation: kappa - .91, self action: kappa - .91, discussion: kappa - .93, seeking support: kappa - .96).

Goals. Participants' responses to a question regarding the goal of the protagonist were evaluated. For each problem, participants were asked to respond to the following question “What is Joe's (or Susan's, Rebecca's or Michael's) goal in solving this problem?" Answers were open-ended and not limited in form or length and the bottom half of the page was left blank for participants' responses. Responses were transcribed for coding purposes.

Goal Coding. Goals were coded to assess two dimensions: the degree to which the goal was self-focused and/or other-focused. Other studies examining goals suggest that a participant's goals might contain more than one dimension (Berg et al., 1998; Strough et al., 1996). Categorizing a goal as either "self" or "other" focused may not adequately capture a response that includes both self and other-focused concerns. For example, goals 
may be high in one dimension and low on the other (i.e. high self-focus, low other-focus), or high or low in both dimensions (i.e. high self-focus, high other-focus).

Each dimension of goal responses was coded using a three-point scale. Responses to the question regarding goals for the problem were scored for degree to which the goals were self- and other-focused. A score of 1 (no mention) indicated that there was no mention of the goal type in the participant's response, a score of 2 (little mention) indicated some mention of a goal type in the response, and a score of 3 (major mention) indicated that the goal type was predominant in the response. For example, the response "Joe should think about what is best for his career" received a score of 1 for otherfocused ( 1 = the desired outcome does not consider the needs of the others). A score of 2 ( 2 = the desired outcome includes some concern for the needs of others) was given to a statement such as "Seeing to her [Rebecca's] mother's well being and her own peace of mind that she did the right thing". Finally, a score of 3 for other-focused $(3=$ the desired outcome emphasizes consideration of others and their needs) was given to responses such as "Talk it out with her mother and see what she [the mother] wants to do". Scores were assessed for both the work and caregiving questions, so that each participant received four scores for their goal response. The scores were not summed across the two problem domains, and scores for self and other focus were not highly negatively correlated, so the scores were not combined.

For example, each participant had two written goal responses (one for the work question, one for the caregiving question). The coding process involved looking at one response (work) and deciding the degree to which other-focused goals were expressed in the response, on a scale from 1-3. Then the same response was evaluated for the 
prevalence of self-focused goals, again assigning a score between 1 and 3 . The process was then repeated for the participant's second response (caregiving). Reliability guidelines similar to those established in the strategy coding section (see above) were used to establish reliability for goal coding. An undergraduate research assistant was trained in the goal coding scheme (using training data from Strough, 2006) and reliability was established with the primary researcher on $20 \%$ of study data, using intraclass correlation as the measure of reliability, before independent coding began. The coders were instructed not to consider participants' strategies in determining goal scores. The remainder of the goals data was coded by the undergraduate research assistant. See Appendix B for goals coding guide.

\section{Procedure}

Older adult participants in this study were either given or mailed a packet containing the consent forms, instructions, and the questionnaire. After completing the questionnaire, participants returned the packet in a prepaid envelope addressed to the principal investigator. Older adults were entered into a drawing for a $\$ 100$ gift certificate as a thank you for their participation. Younger adult participants signed up for the study, received information regarding the time and location when they could pick up a study packet (from the researcher's lab in the Psychology Department of West Virginia University), took the packet home to fill out, and returned the packet to the researcher by returning to the same lab room. The procedure for the younger adults was put into place in order to mirror the conditions of the mailed packets given to older adult participants. The young adult participants were given extra credit for psychology courses in exchange for their participation. Complete directions for the measures were given in writing, and 
informed consent was obtained for each participant. Participants were also told to complete the packet on their own, and were asked to sign a form indicating that they had completed the packet independently.

Participants were asked to complete the questionnaire containing the problemsolving vignettes, the BSRI, and demographic information, in that order. There were two forms of the questionnaire and participants were randomly assigned to each condition. Form A presented the work vignette with a male as the protagonist of the story and the caregiving vignette with a female as the protagonist of the story. Form B included the exact same vignettes, but with a female as the protagonist for the work vignette and a male as the protagonist for the caregiving vignette. Although equal distribution of form type was intended, the actual distribution of form type in the returned packets was not exact, especially for younger adults (see Table 4). This was a function of younger adults waiting until the last week of the semester to return packets. Data collection for younger adults occurred over five weeks (towards the end of the semester), with 53 packets returned in the last week of data collection. As of the fourth week of data collection, there were an inadequate number of younger adults, and because it appeared that the conditions were not being filled, more packets were handed out than originally planned. However, more packets were returned in the last week of data collection than in the previous two weeks, resulting in a much larger sample size for younger adults than was anticipated.

Results

\section{Design and Variables}

The categorical between-subject variables for this study included age (young adult, older adult), sex (male, female), and form type (gender stereotypical, non- 
stereotypical problem). The manipulated independent variable of domain of the vignette (work, caregiving) was a within-subjects factor in this study. Proportion scores for problem-solving strategies served as dependent variables and a continuous overall score was used to determine goal orientation.

\section{Missing Data}

For this study, 217 participants provided responses to at least one of the problem situations. However, for the work problem, one participant's response was classified as a comment as opposed to a strategy, and so did not have a strategy score for this problem. This same participant did not provide a response for the caregiving problem. Additionally, two other participants did not include a response for the caregiving problem. These three participants were not included in the following analyses Selection of Strategies for Analysis

As mentioned previously, participant responses were coded using a coding scheme with 16 possible classifications (15 strategy categories and 1 classification for comments). Of these categories, it was expected that the majority of strategy responses would fall into four different categories, deliberation, self action, discussion, seeking support. This expectation was met with these four strategies accounting for $92 \%$ of coded strategy responses: deliberation (20\%), self action (30\%), discussion (20\%), and seeking support (22\%). Additional strategies would have been considered for inclusion in the analyses had they accounted for at least $20 \%$ of strategy responses, however no additional strategies met this requirement: self assertion (4.1\%), deliberate non-action $(2.3 \%)$, managing emotions (.4\%), ignore (.3\%), accepting influence (.6\%), aggression $(.04 \%)$, 
acceptance $(0 \%)$, leave $(0 \%)$, verbal aggression $(0 \%)$, crime $(0 \%)$, other $(.4 \%)$, and comment $(2.1 \%)$.

Of the four strategies making up the majority of responses, the two interpersonally-oriented strategies were subsequently used in the primary analyses and mediation model. These strategies were selected for use in the analyses because of previous research (Berg \& Calderone, 1994; Berg et al., 1998; Strough et al., 1996) suggesting that age and gender differences could be expected for interpersonal strategies and goals, but also because of research suggesting that age or sex alone may not be the only factors could also contribute to differences in participant responses (Strough et al., 1996).

\section{Normality of Data and Outliers}

Test of normality were conducted for each of the dependent variables in the study. Visual inspection of histograms indicated that both other-focused goal scores for the work problem $(M=2.75, S D=.53)$ and the caregiving problem $(M=2.92, S D=.33) \mathrm{did}$ not appear to be normally distributed. Additionally, skewness (for work goals=-2.09; for caregiving $=-4.16$ ) and kurtosis (work=3.48; caregiving=18.03) values were not equal to zero. This distribution occurred because more participants had scores of 3 (major mention) for these goals than scores of 2 (little mention) or 1 (no mention). Histograms for the four strategies did not initially appear to be normally distributed, and skewness and kurtosis values for the four strategies were not equal to zero (discussion for work: skewness $=.770$, kurtosis $=.160$; seeking support for work: skewness $=1.83$, kurtosis $=5.14$; discussion for caregiving: skewness $=1.79$, kutosis $=3.37$; seeking support for caregiving: skewness $=.148$, kurtosis $=-.286)$. 
These results, however, were primarily due to the number of zero scores. If participants did not list any strategies that were coded as discussion or seeking support, then their proportion score was also a zero. This was especially true for seeking support scores for the work problem and discussion scores for the caregiving problem. These results are not a concern for the study, however, as Tabachnick and Fidell (2001) state that deviation from normality should not substantially effect the analyses when the sample size in large (over 200 participants), as is the case in this study ( $\mathrm{N}=217)$. Finally, for the initial multivariate analysis, the assumption of homogeneity of variancecovariance matrices was violated, however, Tabachnick \& Fidell (2001) suggest that this test might be too strict when sample size is large, as was the case for this study.

For discussion strategies for the work problem, there were no univariate outliers. There were, however, univariate outliers for discussion strategies for the caregiving problem, and for seeking support strategies for both the work and caregiving problems. These outliers were the result of participants responding to the problems with strategies falling only into one category, and therefore resulting in a proportion score of "one" for the problem.

A multivariate test for outliers was conducted using Mahalanobis distance. Tabachnick and Fidell (2001) state that the criterion for outliers using this test is $\mathrm{p}<.001$. Based on the analyses used in this study and a chart provided by Tabachnick and Fidell, any value greater than $\chi^{2}(3)=16.266$ would be considered a multivariate outlier. None of the values listed in the output were higher than 11.033 , therefore there were no multivariate outliers in this study. Strategies for the Work and Caregiving Problems 
To test the hypotheses that there would be differences in interpersonally-oriented strategies by age, sex, form type, and domain (Research Question 1), a repeated measures multivariate analysis of variance (MANOVA) was conducted. The MANOVA was a 2 (age: young, old) x 2 (sex: male, female) x 2 (form type: gender stereotypical, nonstereotypical problem) x 2 (domain: work, caregiving) design. Four strategies were included in the analyses as dependent variables: discussion and seeking support strategies for the work problem and discussion and seeking support strategies for the caregiving problem. Using Wilks' Lamda as the selected criterion (Tabachnick \& Fidell, 2001), significant effects were found for domain, Wilks' $\Lambda=.888, F(1,206)=25.97, p<.001$, and domain by strategy, Wilks' $\Lambda=.561, F(1,206)=161.34, p<.001$. However, these findings were qualified by two significant three-way interactions, one for domain by strategy by sex, Wilks' $\Lambda=.978, F(1,206)=4.55, p<.034$, and one for strategy by age by sex, Wilks' $\Lambda=.971, F(1,206)=6.11, p<.014$. To follow-up the domain by strategy by sex interaction, two 2 (domain) x 2 (sex) repeated measures ANOVAs were conducted. The first analysis examined discussion strategy proportion score as the dependent variable; the second analysis examined seeking support strategies. To follow up the strategy by age by sex interaction, two 2 (age) x 2 (sex) ANOVAs were conducted. Discussion strategy proportion scores were examined in the first ANOVA, and seeking support strategy proportion scores were examined in the second ANOVA.

Discussion strategy by domain x sex. A 2 (domain) x 2 (sex) repeated measures ANOVA was conducted, with discussion strategy proportion scores as the dependent variable. The only significant effect was found for domain, Wilks' $\Lambda=.806, F(1,212)=$ $51.10, p<.001$. This result indicated that participants were more likely to report 
discussion strategies for the work domain $(M=.265, S D=.247)$ than for the caregiving domain $(M=.133, S D=.210)$.

Seeking support strategy by domain x sex. A 2 (domain) x 2 (sex) repeated measures ANOVA was conducted, with seeking support strategy proportion scores as the dependent variable. Results indicated a significant interaction for domain and sex, Wilks' $\Lambda=.983, F(1,212)=181.66, p<.05$. Follow-up univariate ANOVAs were conducted to compare the proportion of seeking support strategies for men and women in each domain. For the work problem (Tables 5 and 6), sex differences were significant, $F(1,212)=$ $9.21, p<.003, \eta^{2}=.04$. Men $(M=.134, S D=.182)$ were more likely to report seeking support strategies in the work domain than were women $(M=.077, S D=.118)$. For the caregiving problem, sex was not significant. There was no significant difference between men $(M=.357, S D=.211)$ and women $(M=.368, S D=.238)$ for seeking support strategies when responding to the caregiving vignette.

Discussion strategy by age and sex. A 2 (age) x 2 (sex) univariate ANOVA was conducted, with discussion strategy proportion scores, collapsed across domain, as the dependent variable (see Tables 7 and 8). Results indicated a significant age by sex interaction, $F(1,210)=11.70, p<.001, \eta^{2}=.053$. Independent-samples t-tests were conducted to compare age differences for men and women. For men, the test was significant, $t(92)=-3.59, p<.001$. Older men $(M=.26, S D=.20)$ had larger proportion scores for discussion strategies than did younger men $(M=.13, S D=.16)$. For women, the test was not significant. Younger $(M=.23, S D=.20)$ and older women $(M=.18, S D$ $=.15$ ) did not significantly differ in their scores for discussion strategies. 
Seeking support strategy by age and sex. A 2 (age) x 2 (sex) univariate ANOVA was conducted, with seeking support strategy proportion scores, collapsed across domain, as the dependent variable. There were no significant main effects or interactions.

\section{Goals for the Work and Caregiving Problems}

Before conducting the analyses examining problem-solving goals, it was determined that self-focused and other-focused goals were not significantly negatively correlated. To test the hypotheses that there would be differences in other-focused goal scores by age, sex, form type, and domain (Research Question 2), a repeated measures multivariate analysis of variance (MANOVA) was conducted. The MANOVA was a 2 (age: young, old) x 2 (sex: male, female) x 2 (form type: gender stereotypical, nonstereotypical problem) x 2 (domain: work, caregiving) design. Other-focused goal scores for the work question and the caregiving question were the dependent variables. Using Wilks' Lamda as the selected criterion (Tabachnick \& Fidell, 2001), significant effects were found for domain, Wilks' $\Lambda=.941, F(1,202)=12.75, p<.001$. Other-focused goals scores were significantly higher when participants were responding to the caregiving problem $(M=2.91, S D=.33)$ as opposed to the work problem $(M=2.77, S D=.51)$.

\section{Testing the Mediation Model}

To address whether other-focused goals mediated differences in interpersonallyoriented strategies (Research Question 3), a number of steps had to be completed to establish mediation (Baron \& Kenny, 1986). The repeated measures MANOVA, described in the previous section, established that the proportion score of seeking support strategies for the work problem varied by sex and the proportion score for discussion strategies varied by domain. Thus, the first requirement of the mediation model, a relation 
between the study factors (age; sex; domain) and interpersonally-oriented strategies, was met.

To fulfill the second requirement of mediation, other-focused goals were examined as predictors of interpersonally-oriented strategies. To examine other-focused goals as a mediator of sex differences in seeking support strategies in the work domain, a regression analysis was conducted with other-focused goals as the predictor and seeking support strategy proportion scores as the criterion variable. Other-focused goals were not significantly associated with seeking support strategies in the work domain, $R^{2}=.009$.

To examine other-focused goals as a mediator of domain differences in discussion strategies, two regressions were conducted. The first regression was conducted with other-focused goals for the work problem as the predictor and discussion strategy proportion scores for the work problem as the criterion variable. The second regression was conducted with other-focused goals for the caregiving problem as the predictor and discussion strategy proportion scores for the caregiving problem as the criterion variable. Results for both regressions were not significant $\left(R^{2}=.000\right.$ for work; $R^{2}=.010$ for caregiving), indicating that other-focused goals do not serve as a mediator of domain differences in discussion strategies.

To examine other-focused goals as a mediator of age and sex difference in discussion strategies, regression was conducted with a combined score for other-focused goals collapsed across domain as the predictor and a combined score for discussion strategies as the criterion variable. This analysis was also not significant.

Because other-focused goals were not associated with interpersonally-oriented strategies, the second requirement of the mediation model was not met (Baron \& Kenny, 
1986). Thus, in contrast to the hypothesis (Research Question 4), other-focused goals did not mediate age, sex, and domain differences in interpersonally-oriented strategies. Additional Analyses - Instrumentally-Oriented Strategies

The primary focus of the study was to examine differences in interpersonallyoriented strategies and other-focused goals, and to examine the mediation model for other-focused goals. Although instrumentally-oriented strategies were not included in the mediation model, differences in these strategies were also examined. To test for differences in instrumentally-oriented strategies by age, sex, form type, and domain, a repeated measures MANOVA was conducted. The MANOVA was a 2 (age: young, old) x 2 (sex: male, female) x 2 (form type: gender stereotypical, non-stereotypical problem) x 2 (domain: work, caregiving) design. The four strategies included in the analyses as dependent variables: deliberation and self action strategies for the work problem and deliberation and self action strategies for the caregiving problem. Results indicated three significant three-way interactions, domain by strategy by sex, Wilks' $\Lambda=.981, F(1,212)$ $=4.00, p<.047$, domain by strategy by age, Wilks' $\Lambda=.981, F(1,212)=4.08, p<.045$, and strategy by sex by form type, Wilks' $\Lambda=.969, F(1,206)=6.57, p<.011$. To followup the domain by strategy by sex interaction, two 2 (domain) $x 2$ (sex) repeated measures ANOVAs were conducted. The first analysis examined deliberation strategy proportion score as the dependent variable; the second analysis examined self action strategies. To follow up the domain by strategy by age interaction, two 2 (strategy) $x 2$ (age) repeated measure ANOVAs were conducted, the first analysis with work strategies as the dependent variable and the second analysis with caregiving strategies as the dependent variable. Finally, to follow up the strategy by age by form type interaction, two 2 (sex) by 
2 (form type) univariate ANOVAs were conducted. The first analysis examined deliberation scores, collapsed across domain, as the dependent variable; the second analysis examined self action strategy scores collapsed across domain.

Deliberation strategy by domain $x$ sex. A 2 (domain) x 2 (sex) repeated measures ANOVA was conducted, with deliberation strategy proportion scores as the dependent variable. The only significant effect was found for domain, Wilks' $\Lambda=.835, F(1,212)=$ $41.94, p<.001$. This result indicated that participants were more likely to report deliberation strategies for the work domain $(M=.242, S D=.262)$ than for the caregiving domain $(M=.117, S D=.203)$.

Self action strategy by domain x sex. A 2 (domain) x 2 (sex) repeated measures ANOVA was conducted, with self action strategy proportion scores as the dependent variable. Results indicated a significant interaction for domain and sex, Wilks' $\Lambda=.973$, $F(1,212)=5.91, p<.016$. Follow-up univariate ANOVAs were conducted to compare the proportion of self action strategies for men and women in each domain. For the caregiving problem, sex differences were significant, $F(1,212)=6.52, p<.011, \eta^{2}=.03$. Men $(M=.381, S D=.243)$ were more likely to report self action strategies in the caregiving domain than were women $(M=.298, S D=.230)$. For the work problem, sex was not significant. There was no significant difference between men $(M=.251, S D=$ $.294)$ and women $(M=.276, S D=.268)$ for self action strategies when responding to the work vignette.

Work domain by strategy $x$ age. A 2 (strategy) x 2 (sex) repeated measures ANOVA was conducted, with work strategy proportion scores as the dependent variables. Results indicated a significant interaction for strategy and age, Wilks' $\Lambda=$ 
$.979, F(1,212)=5.06, p<.025$. Follow-up univariate ANOVAs were conducted to compare the proportion of work strategies for older and younger adults. For deliberation strategy scores for the work problem, age was significant, $F(1,212)=5.64, p<.018, \eta^{2}=$ .026 . Older adults $(M=.297, S D=.273)$ were more likely to report deliberation strategies in the work domain than were younger adults $(M=.209, S D=.251)$. For self action strategy scores in the work problem, age was not significant. For the work problem, there was no significant difference between older adults $(M=.227, S D=.259)$ and younger adult $(M=.287, S D=.289)$ for self action strategies.

Caregiving domain by strategy $x$ age. A 2 (strategy) x 2 (age) repeated measures ANOVA was conducted, with caregiving strategy proportion scores as the dependent variables. Results indicated a significant interaction for strategy and age, Wilks' $\Lambda=$ $.865, F(1,212)=33.13, p<.001$. Follow-up univariate ANOVAs were conducted to compare the proportion of caregiving strategies for older and younger adults. For deliberation strategy scores for the caregiving problem, age was significant, $F(1,212)=$ $31.50, p<.001, \eta^{2}=.129$. Older adults $(M=.212, S D=.238)$ more likely to report deliberation strategies in the caregiving domain than were younger adults $(M=.061, S D$ $=.155)$. For self action strategy scores for the caregiving domain, age was significant $F(1,212)=17.20, p<.001, \eta^{2}=.075$. Younger adults $(M=.384, S D=.237)$ were more likely to report self action strategies for the caregiving problem than were older adults $(M$ $=.248, S D=.219)$.

Self action strategy by sex and form type. A 2 (sex) x 2 (form type) univariate ANOVA was conducted, with self action strategy proportion scores, collapsed across domain, as the dependent variable. Results indicated a significant sex by form type 
interaction, $F(1,210)=7.247, p<.008, \eta^{2}=.033$. To follow-up on this interaction, independent-samples t-tests were conducted to compare sex differences for gender stereotypical or non-stereotypical form type. For women, the test was significant, $t(118)$ $=3.14, p<.002$, indicating that women who responded to the gender stereotypical form $(M=.345, S D=.189)$ had greater scores for self action strategies than women who responded to the non-stereotypical form $(M=.238, S D=.183)$. For men, the test was not significant. Men responding to the gender stereotypical form $(M=.297, S D=.217)$ and the non-stereotypical form $(M=.337, S D=.209)$ did not significantly differ in their scores for self action strategies.

Deliberation strategy by sex and form type. A 2 (sex) x 2 (form type) univariate ANOVA was conducted, with deliberation strategy proportion scores, collapsed across domain, as the dependent variable. There were no significant main effects or interactions. Exploratory Analyses - Number of Strategies

For the primary analyses, the dependent variable was the proportion of a given strategy. Additional exploratory analyses were conducted, with total number of strategies for each category (discussion and seeking support) as the dependent variables, to determine whether the results for strategy fluency were similar or different to those reported above. When using total number of strategies, the same results as the analyses using strategy proportion scores (described previously) were obtained. Two significant three-way interactions (domain by strategy by sex; strategy by age by sex) were observed in the overall analysis. Follow-up tests determined that participants were more likely to report a greater number of discussion strategies for the work domain than for the caregiving domain, that older men had a greater number of discussion strategies 
collapsed across domain than younger men and that men reported a greater number of seeking support strategies than women when responding to the work problem.

Finally, average length of responses (total number of strategies) indicated that younger men $(M=4.79, S D=2.38)$ did provide fewer strategies on average than younger women $(M=5.53, S D=2.06)$, older men $(M=5.82, S D=2.90)$, and older women $(M=$ $5.96, S D=2.69)$.

\section{Discussion}

This study set out to examine differences in everyday problem-solving, specifically how age and sex of participants, gender stereotype roles for the protagonist, and domain of the problem may influence the generation of problem-solving goals and strategies. The study examined whether interpersonally-oriented goals (goals focused on the needs and concerns of others) would be related to other-focused strategies, whether such goals would serve as mediators of any age, sex, form type, or domain differences observed in interpersonally-oriented strategies. Finally, the study examined whether previously observed differences in problem-solving goals and strategies would be found when the problem vignettes were held constant for all participants (Berg et al., 1998; Strough et al., 1996), and participants were allowed to generate their own solutions for the problem (Blanchard-Fields et al., 2007).

Strategies for Solving Work and Caregiving Problems

Domain, sex, and strategies. When responding to the problem vignettes, participants' responses varied by domain. First, when participants were responding to the work problem, they reported more discussion strategies than when they were responding to the caregiving question. This was somewhat unexpected as an interaction of form type 
(as an indicator of prescriptive stereotypes) and domain was anticipated. Domain differences in discussion strategies may reflect the character of the problem as was portrayed in the vignette. The work problem involved a number of people in the immediate problem (i.e. wife, children, parents) that could potentially be affected by the protagonist's decision. This might account for participants mentioning more discussion strategies for this problem - more people to consider, so more discussions with these people about the moving decision. For the caregiving problem, the mother who needs care was the only person mentioned. Thus, there may have been fewer opportunities to discuss the problem, because fewer parties were explicitly involved.

Second, differences in seeking support strategies varied by sex and problem domain. Men reported more seeking support strategies than women when responding to the work domain. This could indicate that men were more likely to seek out additional information about the problem in their attempt to deal with the situation. For example, a number of men included responses such as "ask others in the company about the Chicago office", "ask his boss if he can visit the new office" and even "contact Chicago chamber of commerce about housing taxes". Although these strategies were classified as seeking support in the current study because help for the problem is being sought from others outside of the problem, they do contain an element of seeking information. Seeking information could be considered as more of an instrumentally-oriented strategy. In work by Aldwin and Revenson (1987), they used a category called support mobilization to describe any responses where information, advice, and/or emotional support was sought from other individuals. It may be more accurate, in future work with the current data, to use a similar classification of seeking advice, which would allow for a distinction 
between searching for general information and asking another person for specific information regarding how to solve the problem. Another consideration might be the way men chose to use seeking support strategies. It is possible that seeking support strategies were seen as another way of trying to fix the problem (in other words, strategies that were more action oriented) rather than just talking about the problem. This type of strategy response -"ask the boss if he could do the same thing [in the current location]" - involves the protagonist seeking support from the boss, but it also involves an attempt to fix the problem presented in the situation.

Unlike the work problem, there were no significant age or sex differences for seeking support strategies for the caregiving problem. The nature of the caregiving problem itself might account for the lack of differences in this type of strategy. The problem dealt with a medical condition (a stroke) and medical care. It is possible that this aspect of the problem might have led participants to look to "expert" sources to better understand what course of action to take to solve the problem. Indeed, many of the strategy responses for this problem sought advice, information, and assistance from doctors, nurses, in-home caregivers, and nursing home workers. Issues involving health, elder care, and caregiving responsibilities were very important to understanding this problem situation, and subsequently determining strategies for the protagonist to pursue (Lawrence et al. 2002). So it may be that when a problem includes an aspect requiring expertise, this aspect of the problem overrides any age and sex differences in strategies. Age, sex, and strategies. As expected, a greater proportion of older adult men strategies involved discussion than did those of younger adult men. One explanation may be that older adult men were more likely to consider all of the people involved in the 
situation. As a result of experience with the problem, or similar problems, older adult men may have thought of more people who the protagonist needed to consult with before making a decision about relocating the family. Nearly half of older adult men (work $43.2 \%$; caregiving $-48.6 \%$ ) in the study indicated personal experience with the problem as opposed to younger adult men (work $-33.3 \%$; caregiving $-21.1 \%$ ). Other studies have considered life experience of older adults in interpreting age differences in problemsolving strategies (Blanchard-Fields et al., 2007). Young adult men, on the other hand, may have been less likely to consider issues involving others in the problem, as younger adults have been found to be somewhat self-focused and concerned with issues of achievement and independence (Zirkel \& Cantor, 1990). Another possibility is that younger adult men simply wrote shorter responses than other participants. As determined by an exploratory analysis mentioned earlier, younger men did provide fewer strategies on average than younger women and older adults in the study.

It was also expected that a greater proportion of older adult women's strategies involved discussion than did those of younger adult women, but no significant differences were found. Women of both age groups indicated similar considerations of other people in the problem who need to be consulted as part of the problem-solving process. The lack of any age differences between women in the study is an interesting finding. Due to the cross-sectional design of the study, no conclusions regarding women's problem-solving over time can be made. However, changes - or lack of changes - in women's responses to fixed problem vignettes over time might be examined in the context of a longitudinal design in future research. 
Finally, although significant differences were found for some of the hypotheses, it is important to note that effect sizes for the significant results were relatively small in comparison to other everyday problem-solving studies comparing younger and older adults (see review in Thornton \& Dumke, 2005). This may indicate that the age and sex differences highlighted in this data set are ultimately not important in everyday problem solving. Although this apparent lack of important differences might indicate that fixed problem vignettes may result in fewer problem-solving differences being found, medium effect sizes for other studies using fixed problem vignettes (Blanchard-Fields et al., 1995; Cornelius \& Caspi, 1987) could limit this conclusion..

Goals used for Work and Caregiving Problems

Another important aspect of the current study was the investigation other-focused goals for the work and caregiving problems. Unlike the results for interpersonallyoriented strategies, goal responses did not vary based on age or sex, however there were differences for domain. Other-focused goal goals scores were significantly greater when participants responded to the caregiving problem as opposed to the work problem. This was somewhat surprising, as both problems described other individuals that the protagonist could consider in determining goals for the situation. Although there were more "others" in the work problem (spouse, children, parents, etc.), it is possible that concern for the mother's well-being in the caregiving problem prompted more focus on her needs when participants were describing goals for the problems.

Significant age and sex differences did not emerge for other-focused goals and many participants had relatively high scores for these types of goals (e.g., 75\% of participants had average goal scores $=3$ ). The tendency to have high other-focused goal 
scores could be the result of participants responding to the interpersonal aspects of the two problem vignettes. A study by Strough and colleagues (1996) found that when interpersonal aspects of problems were important to participants, they responded by reporting interpersonal goals for the problem. Additionally, Strough and colleagues discussed how goals classified as other-focused might also contain other concerns (i.e. task completion). Although the coding of goals in the current study assessed both otherand self-focused goals, it is still possible that other-focused goals reflected numerous concerns that were not immediately apparent to the coders.

\section{Assessing the Mediation Model for Other-focused Goals}

In addition to determining differences in other-focused goals and interpersonallyoriented strategies, this study also examined whether goals mediated differences observed in strategies. This evaluation followed the steps outlined by Baron and Kenny (1986). As discussed in the previous section, age, sex, and domain differences in interpersonallyoriented strategies were established, and so the first requirement of the mediation model was met. For the second step of the process, other-focused goals were examined to see if they would be associated with interpersonally-oriented strategies. It was expected that this relation would be established, however, there were no significant associations between other-focused goals and interpersonally-oriented strategies for either the work or caregiving problem. As a result, the requirements for testing the mediation model were not met for this study.

Unlike Berg et al's (1998) study, the current research did not find a relation between other-focused goals and interpersonally-oriented strategies. In that study, participant goals were classified as being either interpersonal or competence, and by their 
own admission this accounted for only a minority of the goals responses. In the present study, goals were coded so as to allow for responses that identified more than one type of goal. However, in doing so, the coding process for the study might have been too inclusive, resulting in relatively high other-focused scores for most of the participants in the study. Future research will need to consider the consequences of how goals are evaluated and what impact that may have on the association between goals and strategies.

\section{Limitations of the Study}

There are a number of limitations to be considered for the present study. It was expected that this study would illustrate a mediation model in which other-focused goals would account for any differences in interpersonally-oriented problem solving. Although this expectation was not met, it is possible that other variables might mediate age differences problem-solving strategies. In the current sample, older adults were significantly more educated than the younger adults, and the idea that education could be associated with problem-solving ability has been suggested in previous research (Diehl, Marsiske, Horgas, Rosenberg, Saczynski, \& Willis, 2005). However, there were no significant correlations between education and other-focused goals or interpersonallyoriented strategies. Education may also have been a factor in participants' similar responses to the stereotyped and non-stereotyped forms of the vignette (Burgess \& Borgida, 1999). Future research could further examine education as well as other potential mediators, such as experience with the study problems.

Cognitive factors, such as memory, verbal ability, and writing ability, might be important in understanding participants' responses to the two problem-solving vignettes. Participants' responses to the questions regarding goals and strategies for the problem 
required them to accurately read and process the vignette and provide an open-ended written response. Differences in writing ability might account for such findings as the strategy differences between younger and older adult men. However, cognitive measures were not included in this study, so it is not possible to follow up on the relationship between cognitive abilities and participant responses.

Additional covariates also might be examined in future work with this data. As mentioned previously, experience may be of importance in examining responses to these problem situations. Another possible covariate might be masculine and feminine personality traits. In addition to biological sex as an identifier of gender, masculinity and femininity might also affect how participants respond to the problem situations. It may be important to explore whether these personality traits will influence responses. For example, perhaps age differences between older and younger men for discussion strategies may be accounted for by their personality traits. In addition to the problemsolving vignettes, participants in this study also completed the Bem Sex Role Inventory (Bem, 1976), so future work with this data set will be able to further explore masculine and feminine personality traits as possible covariates of interest.

Finally, the current study examined whether participants' goals would serve as a mediator of differences in problem-solving strategies, but did not find this to be the case. However, rather than look for mediation, future work might focus on goals as a moderator of differences. Whereas mediation indicates that a variable other than the independent variable is accounting for all of the difference in the dependent variable, moderation would mean that the effect of the independent variable (i.e. age, sex) on the dependent variable (strategies) depends on the level of the third variable (goals). Factors 
such as experience, education, and personality traits could also be examined as moderators for problem-solving responses.

Another possible limitation to this study might be the coding scheme used for the strategies. Although the coding scheme has been used in previous problem-solving research (Strough, 2007) and is similar to broader coding schemes used in related studies (Berg et al., 1998; Blanchard-Fields et al., 1995; Patrick \& Strough, 2004), the scheme was not specifically created for this study. Because the study asked participants to generate strategies for the protagonist of the two fixed problem (rather than suggesting strategies for a problem in their own life), there were some strategies that might have been better described by additional categories. For example, a participant might have responded to the caregiving question with a strategy classified as 'seeking support because it involved putting Mrs. Clark in a nursing home. However, this coding did not address whether this solution was the result of all three parties involved deciding that the assistance of a nursing home was preferred to home care, or was it the result of the protagonist independently deciding that the option of seeking support was preferable to dealing with Mrs. Clark directly. Coding procedure dictated that statements be judged on what was written on the page more than what might be "implied" by the statement, but this example demonstrates some of the difficulties of using a coding system to classify written responses where further clarification of what the strategy entails is impossible. Future studies may benefit from an interview format (e.g. Berg, Meegan, \& Klaczynski, 1999) where the researcher can ask participants follow-up questions and request clarification is a response is confusing or ambiguous. 
Although the coding scheme including a category for emotion, very few responses fell into this category. This is somewhat surprising considering that other researcher have found emotion-regulation strategies as common problem-solving strategies, especially for older adults (Berg et al, 1998; Blanchard-Fields et al., 1995). The difference might be the result of the structure of the problems in the current study. Participants were asked to respond to a problem where a main protagonist was the one "experiencing" the problem, and then asked to generate goals and strategies for the protagonist in the problem. Other studies (Crawford \& Channon, 2002) have found little difference in participant responses when asked what a character should do in a problem and what they themselves would do. However, it is possible that emotion-regulation strategies were not observed in this study because participants were not specifically asked to consider their own personal reactions to the problem situations.

As discussed previously, hypothetical vignettes have been used in many previous problem-solving studies (i.e. Blanchard-Fields et al., 1995, 2007; Cornelius \& Caspi, 1987). Although vignettes can be a useful study tool, there are also limitations to their use. Hypothetical vignettes may not adequately capture all of the contextual factors found in a "real life" problem as experienced by the participant. Such vignettes can only present the immediate problem and not the individual's knowledge of the situation, mood, and other specific factors. In one problem-solving study (Diehl, Willis, \& Schaie, 1995), the researchers validated a paper and pen self-report measure (Instrumental Activities of Daily Living) by way of an observed measure (Observed Tasks of Daily Living), however this was to evaluate older adults' ability to complete daily life tasks and not interpersonal everyday problems. Vignettes are also limited in dealing with the 
emotional issues that can be present in an individual's response to a problem. Although research by Blanchard-Fields and colleagues (1995) has examined manipulations of emotional salience, hypothetical vignettes may not be able to fully recreate the emotional experience of a "real life" problem situation. In the current study, the lack of emotional strategies reported by participants may indicate that this aspect of context may be limited.

An effort was made to match the method of delivery for all participants in the study, and a mailed packet system was seen as an advantage since participants did not have to leave home to participate in the study. Additionally, the packets were randomly assigned to participants as they were mailed or given out. However, response rates were such that it was difficult to maintain equal sample sizes for each group within the study. Data collection for younger adults took place over five weeks, and up until the last week, many packets were still needed, especially for men. However, since extra credit was not due until the end of the semester (the last week of data collection for young adults), many packets were not returned until that week, resulting in a much larger number of younger adults than anticipated. Although efforts were made to gain additional older adult participants, it was not possible to obtain equivalent numbers of older and younger adults in the time frame available. However, the current data set included sufficient participants for initial power analysis and statistical procedures in the analysis adjusted for unequal $\mathrm{n}$ (Tabachnick \& Fidell, 2001).

Although sex was included in the model used for this study, its inclusion could be debated based on the concept of sex as a proxy variable. Sex is often used to categorize individuals in research studies as either male or female. However, other studies have used categorization by sex as a proxy for gender, since the two are considered to be strongly 
related (Reevy \& Maslach, 2001). Just as numeric age may serve as a proxy for experience in certain specific situations (Baer, 1970; Baltes, Reese, \& Nesselroade, 1998), sex may serve as a proxy for a number of other qualities such as personality traits, expressiveness, and instrumentality, to name a few. In studies hoping to examine "gender" differences, it may be beneficial to consider other aspects of gender, otherwise researchers may perpetuate stereotypes of gender differences.

Finally, this study was limited to a cross-sectional design and therefore cohort differences are confounded with age differences (Schaie \& Caskie, 2004). It is a possibility the age differences in the study might be cohort differences. However, without a longitudinal design such differences cannot be determined.

\section{Future Directions}

This study set out to examine whether age and sex differences that have been found in previous problem-solving studies using open-ended vignettes and responses (Berg et al., 1998; Strough et al., 1996) or fixed strategy responses (Blanchard-Fields et al., 2007), would be found in open-ended responses to fixed problem vignettes. If this question is to be addressed in the future, perhaps the best method would be to include all of the methodology aspects into the same study. A study could be constructed where similarly matched participants could be placed in one of four everyday problem-solving conditions: fixed vignette and fixed strategies, fixed vignette and open-ended strategies, open-ended vignette and fixed strategies, or open-ended strategies and open-ended vignettes. This type of design, addressing issues of problem-solving methodology, may allow for better understanding of differences in everyday problem solving. 
Another consideration for future work in this area would be to link other-focused goals and interpersonally-oriented strategies to the ultimate outcome of the problem. One drawback of the questionnaire used in this study was that participants were not asked what ultimate decision they would make regarding the problem situations. If participants had been asked to make a decision regarding the problem (i.e. Joe and his family move to Chicago, Rebecca and her husband care for Mrs. Clark in their own home, etc.), that information could be used to understand how goals and strategies ultimately affect how individuals choose to solve problems. This issue might also have been addressed if participants had been asked to indicate the most effective strategy of the list they had provided, as other problem-solving studies have done (e.g. Blanchard-Fields et al, 2007). This study set out to examine differences in everyday problem-solving, specifically how age and sex of participants, gender stereotype roles for the protagonist, and domain of the problem influenced the generation of problem-solving goals and strategies. Although the hypotheses for this study were not wholly supported, the results do indicate that differences in participants' problem-solving goals strategies were still observed when the problem vignettes were held constant for all participants, but future work should consider the importance of methodology and potential mediators in the problem-solving process. 


\section{References}

Abele, A.E. (2003). The dynamics of masculine-agentic and feminine-communal traits: Finding from a prospective study. Journal of Personality and Social Psychology, 85, 768-776.

Aldwin, C. M. \& Revenson, T. A. (1987). Does coping help? An examination of the relation between coping and mental health. Journal of Personality and Social Psychology, 53, 337-348.

Baer, D. M. (1970). An age-irrelevant concept of development. Merril-Palmer Quarterly, 16, 238-245.

Bakan, D. (1966). The duality of human existence. Oxford: Rand McNally.

Baltes, P. B., Reese, H.W., \& Nesselroade, J. R. (1998). Life-span developmental psychology: Introduction to research methods. Hillsdale, NJ: Lawrence Erlbaum Associates, Inc.

Baron, R. M., \& Kenny, D. A. (1986). The moderator-mediator distinction in social psychological research: Conceptual, strategic, and statistical considerations. Journal of Personality and Social Psychology, 51, 1173-1182.

Berg, C. A., \& Calderone, K. S. (1994). The role of problem interpretations in understanding the development of everyday problem-solving. In Mind in context: Interactionist perspectives on human intelligence. Sternberg, R. J. \& Wagner, R. K. (Eds.).

Berg, C. A., \& Klaczynski, P. A. (1996). Practical intelligence and problem solving: Searching for perspectives. Perspectives on cognitive change in adulthood and aging. Blanchard-Fields, F. \& Hess, T.M. (Eds.). 
Berg, C. A., Meegan, S. P., \& Klaczynski, P. (1999). Age and experiential differences in strategy generation and information requests for solving everyday problems. International Journal of Behavioral Development, 23, 615-639.

Berg, C. A., Strough, J., Calderone, K. S., Sansone, C., \& Weir, C. (1998). The role of problem definition in understanding age and context effects on strategies for solving everyday problems. Psychology and Aging, 13, 29-44.

Blanchard-Fields, F., Chen, Y., \& Norris, L. (1997). Everyday problem-solving across the adult life span: Influence of domain specificity and cognitive appraisal. Psychology and Aging, 12, 684-693.

Blanchard-Fields, F., Jahnke, H. C., \& Camp, C. (1995). Age differences in problemsolving style: The role of emotional salience. Psychology and Aging, 10, 173-180.

Blanchard-Fields, F., Mienaltowski, A., \& Seay, R. B. (2007). Age differences in everyday problem-solving effectiveness: Older adults select more effective strategies for interpersonal problems. Journal of Gerontology: Psychological Sciences, 62B, P61-P64

Burgess, D., \& Borgida, E. (1999). Who women are, who women should be: Descriptive and prescriptive gender stereotyping in sex discrimination. Psychology, Public Policy, and Law, 5, 665-692.

Chrysikou, E. G. (2006). When shoes become hammers: Goal-derived categorization enhances problem-solving performance. Journal of Experimental Psychology: Learning, Memory, and Cognition, 32, 935-942. 
Cooper, C., \& Blanchard-Fields, F. (2003). The relationship between age, working memory, schematic beliefs, and dispositional attributions. Poster presented at the meeting of the Gerontological Society, San Deigo, CA, November.

Cornelius, S. W. \& Caspi, A. (1987). Everyday problem solving in adulthood and old age. Psychology and Aging, 2, 144-153.

Cox, M. J., Paley, B., Burchinal, M., \& Payne, C. C. (1999). Marital perceptions and interactions across the transition to parenthood. Journal of Marriage and the Family, 61, 611-625.

Crawford, S., \& Channon, S. (2002). Dissociation between performance on abstract tests of executive function and problem solving in real-life-type situations in normal aging. Aging \& Mental Health, 6, 12-21.

Crick, N. R., \& Dodge, K. A. (1994). A review and reformulation of social informationprocessing mechanisms in children's social adjustment. Psychological Bulletin, 115, 74-101.

Denney, N. W., \& Pearce, K. A. (1989). A developmental study of practical problem solving in adults. Psychology and Aging, 4, 438-442.

Diehl, M., Coyle, N., \& Labouvie-Vief, G. (1996). Age and sex differences in strategies of coping and defense across the life span. Psychology and Aging, 11, 127-139.

Diehl, M., Marsiske, M., Horgas, A. L., Rosenberg, A., Saczynski, J. S., \& Willis, S. L. (2005). The revised observed tasks of daily living: A performance-based assessment of everyday problem solving in older adults. The Journal of Applied Gerontology, 24, 211-230. 
Diehl, M., Owen, S. K., \& Youngblade, L. M. (2004). Ageny and communion attributes in adults' spontaneous self-representations. International Journal of Behavioral Development, 28, 1-15.

Diehl, M., Willis, S. L., \& Schaie, K.W. (1995). Everyday problem solving in older adults: Observational assessment and cognitive correlates. Psychology and Aging, 10, 478-491.

D’Zurilla, T. J., Nezu, A. M., \& Maydeu-Olivares, A. (2004). Social problem solving: Theory and assessment. In E. C. Chang, T. J. D’Zurilla, and L. J. Sanna (Eds.) Social Problem Solving: Theory, Research, and Training. Washington, D. C.: American Psychological Association.

D’Zurilla, T. J., Maydeu-Olivares, A., \& Kant, G. L. (1998). Age and gender differences in social problem-solving ability. Personality and Individual Differences, 25, 241252.

D'Zurilla, T. J., \& Nezu, A. M. (1990). Development and preliminary evaluation of the social problem-solving inventory. Psychological Assessment, 2, 156-163.

Elliott, T. R., \& Shewchuk, R. M. (2003). Social problem-solving abilities and distress among family members assuming a caregiving role. British Journal of Health Psychology, 8, 149-163.

Gilligan, C. (1982). In a different voice: Psychological theory and women's development. Cambridge, MA: Harvard University Press.

Gottlieb, B.H. \& Rooney, J.A. (2004). Coping effectiveness: determinants and relevance to the mental health and affect of family caregivers of persons with dementia. Aging and Mental Health, 8, 364-373. 
Hakim, C. (2006). Women, careers, and work-life preferences. British Journal of Guidance \& Counselling, 34, 279-294.

Hoffman, C., \& Hurst, N. (1990). Gender stereotypes: Perception or rationalization? Journal of Personality and Social Psychology, 58, 197-208.

Labouvie-Vief, G., Hakim-Larson, J., \& Hobart, C. J. (1987). Age, ego level and lifespan development of coping and defense processes. Psychology and Aging, 2, 284-293.

Lang, F.R. \& Carstensen, L.L. (2002). Time counts: Future time perspective, goals, and social relationships. Psychology and Aging, 17, 125-139.

Lawrence, J.A., Goodnow, J.J., Woods, K. \& Karantzas, G. (2002). Distributions of caregiving tasks among family members: The place of gender and availability. Journal of Family Psychology, 16, 493-509.

McMurran, M., Fyffe, S., McCarthy, L., Duggan, C., \& Latham, A. (2001). “Stop \& Think!": Social problem-solving therapy with personality-disordered offenders. Criminal Behaviors and Mental Health, 11, 273-285.

Moskowitz, D. S., Suh, E. J., \& Desaulniers, J. (1994). Situational influences on gender differences in agency and communion. Journal of Personality and Social Psychology, 66, 753-761.

Nurmi, J., Pulliainen, H., \& Salmela-Aro, K. (1992). Age differences in adults' control beliefs related to life goals and concerns. Psychology and Aging, 7, 194-196.

Quinn, D. M., \& Spencer, S. J. (2001). The interference of stereotype threat with women's generation of mathematical problem-solving strategies. Journal of Social Issues, 57, 55-71. 
Patrick, J. H., \& Strough, J. (2004). Everyday problem solving: Experience, strategies, and behavioral intentions. Journal of Adult Development, 11, 9-18.

Pearlin, L.I., Pioli, M.F., \& McLaughlin, A.E. (2001). Caregiving by adult children: Involvement, role disruption, and health. In R.H.. Binstock and L.K. George (Eds.) Handbook of Aging and Social Sciences (5 ${ }^{\text {th }}$ ed.). San Diego, CA: Academic Press.

Pruchno, R. \& Kleban, M.H. (1993). Caring for an institutionalized parent: The role of coping strategies. Psychology and Aging, 8, 18-25.

Reevy, G. M. \& Maslach, C. (2001). Use of social support: Gender and personality differences. Sex Roles, 44, 437-459.

Richards, J. M. (1966). Life goals of American college freshman. Journal of Counseling Psychology, 13, 12-20.

Robert, B. W., O’Donnell, M., and Robins, R. W. (2004). Goal and personality trait development in emerging adulthood. Journal of Personality and Social Psychology, 87, 541-550.

Rubin, K. H., \& Krasnor, L. R. (1983). Age and gender differences in solutions to hypothetical social problems. Journal of Applied Developmental Psychology, 4, 263-275.

Sansone, C., \& Berg, C. A. (1993). Adapting to the environment across the life span: Different process or different inputs? International Journal of Behavioral Development, 16, 215-241. 
Schaie, K. W., \& Caskie, G. I. L. (2004). Methodological issues in aging research. In D. M. Teti (Ed.), Handbook of research methods in developmental psychology (pp. 9-35).

Seijts, G. H. \& Latham, G. P. (2000). The effect of goal setting and group size on performance in social dilemma. Journal of Behavioural Science, 32, 104-116.

Smith, J., \& Baltes, P. B. (1990). Wisdom-related knowledge: Age/Cohort differences in response to life-planning problems. Developmental Psychology, 26, 494-505.

Strough, J., \& Berg, C. A. (2000). Goals as a mediator of gender differences in highaffiliation dyadic conversations. Developmental Psychology, 36, 117-125.

Strough, J., Berg, C. A., \& Sansone, C. (1996). Goals for solving everyday problems across the life span: Age and gender differences in the salience of interpersonal concerns. Developmental Psychology, 32, 1106-1115.

Strough, J., Cheng, S., \& Swenson, L. M. (2002). Preferences for collaborative and individual everyday problem solving in later adulthood. International Journal of Behavioral Development, 26, 26-35.

Tabachnick, B.G., \& Fidel, L.S. (2001). Using multivariate statistics, 4/e. New York: HarperCollins.

Thornton, W. J. L., \& Dumke, H. A. (2005). Age differences in everyday problem-solving and decision-making effectiveness: A meta-analytic review. Psychology and Aging, 20, 8599.

Walker, S., Irving, K., \& Berthelsen, D. (2002). Gender influences on preschool children's social problem-solving strategies. Journal of Genetic Psychology, 163, 197-211. 
Watson, T. L. \& Blanchard-Fields, F. (1998). Thinking with your head and your heart: Age differences in everyday problem-solving strategy preferences. Aging, Neuropsychology, and Cognition, 5, 225-240.

Zirkel, S., \& Cantor, N. (1990). Personal construal of life tasks: Those who struggle for independence. Journal of Personality and Social Psychology, 58, 172-185. 


\section{Appendix A}

Problem Vignette - Work:

Joe version: Joe and Susan both hold full-time jobs in Philadelphia. They both grew up in the local area, and both their parents live in nearby communities. Joe and Susan also have two children, one in $5^{\text {th }}$ grade and one in $10^{\text {th }}$ grade. Then Joe's boss offers him a new position, a promotion from his current place in the company. The job would provide more money and some additional benefits compared to the job position Joe currently holds. The new position, however, is located at an office in Chicago.

Susan version: Susan and Joe both hold full-time jobs in Philadelphia. They both grew up in the local area, and both their parents live in nearby communities. Susan and Joe also have two children, one in $5^{\text {th }}$ grade and one in $10^{\text {th }}$ grade. Then Susan's boss offers her a new position, a promotion from her current place in the company. The job would provide more money and some additional benefits compared to the job position Susan currently holds. The new position, however, is located at an office in Chicago.

\section{Problem Vignette - Caregiving:}

Rebecca version: Rebecca and her husband Michael live in Boston and both hold fulltime jobs. Rebecca grew up in St. Louis, and Rebecca’s widowed mother, Mrs. Clark, still lives in that city. Mrs. Clark has recently suffered a stroke and is having difficulty functioning to the extent that she is no longer able to live independently. Rebecca is an only child and must now decide how best to care for her mother. 
Michael version: Michael and his wife Rebecca live in Boston and both hold full-time jobs. Michael grew up in St. Louis, and Michael's widowed mother, Mrs. Clark, still lives in that city. Mrs. Clark has recently suffered a stroke and is having difficulty functioning to the extent that she is no longer able to live independently. Michael is an only child and must now decide how best to care for his mother. 


\section{Appendix B}

\section{Coding Scheme for Goals}

This coding scheme will be used to evaluate participants' responses to the goal question for each hypothetical vignette. Coders will evaluate each response to determine the prevalence of each goal type in the response, and provide a score for mention of both self-focused goals and others-focused goals.

The following scale should be used to evaluate each response:

$1=$ no mention - There is no mention of the goal type in the response

Self-focused - the desired outcome does not consider the needs of the protagonist WK "to keep his [Joe] family cared for and as happy as possible"

Other-focused - the desired outcome does not consider the needs of the others WK "Joe should think about what is best for his career"

$2=$ little mention - There is some mention of a goal type in the response

Self-focused - the desired outcome includes some concern for the needs of the protagonist

Other-focused - the desired outcome includes some concern for the needs of others

$\mathbf{C V}$ "to decide whether to move her mother [Rebecca] to Boston, so that her mother can adjust well and be cared for"

-some mention of a self-focused goal (moving her mother to Boston would prevent Rebecca having to move)

WK "to decide what is best for Joe and for Joe's family"

WK "keeping family happy and enhancing his career"

CV "seeing to her mother's well being and her own peace of mind that she did the right thing"

-equal weight given to others-focused goal and self-focused goal

$3=$ major mention - The goal type is predominant in the response

Self-focused - the desired outcome emphasizes consideration of the needs of the protagonist

CV "Rebecca should find a solution so that she doesn't have to move"

Other-focused - the desired outcome emphasizes consideration of others and their needs

CV "talk it out with her mother and see what she wants to do"

CV "getting her mother into a facility that will be most convenient for mother" 


\title{
Appendix C
}

\section{Social Problem-Solving Strategy Coding Scheme (Strough, 2006)}

\author{
Overview of Strategy Coding
}

This coding scheme is used to classify strategies for solving everyday problems. This strategy coding scheme is used to categorize strategy responses for the problem vignettes.

Strategy examples from the current study are given to illustrate each strategy classification used in the study. "WK" indicates an example from the work vignette, and "CV" from the caregiving vignette.

\section{Strategy Coding: Number of Strategies}

1. Read the problem vignettes to become familiar with the problems involved and read the section of the transcribed file that lists the strategies for a specified problem.

2. Number of Strategies. Identify whether or not more than one strategy is mentioned. Separate strategies are indicated by conjunctions such as "and," "but," "or," spaces, numbering systems, commas, and separate sentences. Subordinate clauses and prepositional phrases should not be given separate codes. Rather, information provided in subordinate clauses and prepositional phrases should be used to inform the choice of a strategy code. Coding of conjunctions requires some discretion on the part of the coder. That is, a conjunction may not necessarily indicate more than one strategy, (although more often than not "and" does indicate more than one strategy).

Examples of the use of "and" that are not considered as separate categories are: "wrote to the president of the company and he resolved the problem."

Examples of the use of "and" that are considered separate categories are: "discuss the situation with mother and sister;" "pay the rent and the utilities;" "get the daughter treatment and care for the child."

Decision Tools: If the word(s) "to" or "in order to"can be substituted for the word "and" such that the phrase still makes sense, only ONE strategy is present (e.g., "call and make sure" makes sense with the substitution "call to make sure." However if the word "to" is substituted and the phrase no longer makes sense, TWO strategies are present (e.g., call mom to dad). In general, if the word "and" is used to represent more than one action, then two strategies are present.

3. Indicate separate strategies that have been entered on the same line in the transcribed file by placing a slash mark / between the two strategies.

4. Record the total number of strategies in the box in the appropriate column on the strategy coding sheet.

\section{Strategy Coding: Strategy Type}

1. Strategy codes: Assign one strategy code to each strategy. The coding scheme consists of two general strategy categories each of which are composed of several specific strategies (16 total). 


\section{Social Problem-Solving Strategies Coding Scheme}

A. SELF. These strategies involve an attempt by the problem solver to alter or change aspects of the self in order to solve the problem or better match with the aspects of the problem environment.

1. Deliberation (active approach): Regulating one's thoughts, includes thinking about, considering or pondering information about the situation, also includes implied or explicit information gathering such as thinking about the problem before taking action, finding information, thinking about the situation more, paying closer attention, choosing, deciding, or planning. Aspects of the problem that may have not already been taken into account may be considered or thought about in light of new information.

WK "Joe should think about the benefits of taking the new job"

WK "get all details of the new positions"

CV "Rebecca should consider if caring for her mother would work with her job schedule"

CV "look into traveling back and forth"

2. Self-action (active approach): Self-initiated action by the problem solver; actions that involve altering one's own behavior to solve or deal with the demands presented by the problem or actions aimed at changing aspects of the problem environment.

WK "Joe should find out more information about the new job and the Chicago area"

WK/CV "pray about the situation"

WK "Go to Chicago and check things out"

CV "check prices for nursing homes in each area"

CV "go live with his mother till she feels better"

B. OTher PeOple. These strategies reflect attempts to influence other people or include other people in one's attempts to solve the problem or better match with the aspects of the problem environment. This category includes two subcategories: "including other people" and "influencing other people."

3. Discussion (active approach) - Attempts to engage in others who are directly involved in the problem in a non-confrontational way; both one's own point of view and the point of the other person are considered and there is no obvious "agenda", discussing the problem with others may be used as a means of gathering more information

WK "Joe should discuss issues of housing, schools, medical care availability with his wife"

WK "Sit down and talk through problem with wife [Susan]"

WK "Discuss matter with both parents"

WK "get input from all affected family members" 
CV "Rebecca should discuss the situation with her husband"

CV "Michael should discuss the problem with Rebecca - her viewpoint has to be considered"

CV "Michael needs to talk with his mother to see what she wants"

4. Seeking assistance or social support (active approach) Seeking assistance from others (friends, peers, family members, professionals) to assist one in solving the problem, may include giving control over the problem to others and making others responsible for solving the problem.

WK "Hopefully Joe has family or siblings to help with parents"

WK/CV "Seek spiritual guidance from a pastor"

WK "Seek out coworkers that have experienced similar situation"

CV "Rebecca should seek help of social worker, doctors for $24 / 7$ care"

CV "See what other families do in this situation"

CV "check online - perhaps web sites for information"

In addition to the above strategies, twelve other types of strategies codes were included in

the original coding scheme. Although these additional strategy classifications were used in coding participants' responses, they were not analyzed in the current study as they accounted for less than $20 \%$ of the coded responses. 


\section{Appendix D}

\section{Before you begin, please read the following:}

Because we are interested in your responses to these questions, it is very important that you complete these measures by yourself. Please do not discuss your answers with anyone else, or ask anyone to answer questions for you. Finally, please sign the bottom of this form to indicate that you will fill out these measures alone. After this packet is received, this paper will be stored separately from your responses, so that your responses will remain anonymous. Thank you for your cooperation.

I will complete all of the measures in this packet by myself. I will not discuss my answers with anyone else, or ask anyone to answer questions for me.

Print name:

Signature:

Date: (month/ day/ year) 


\section{Social Problem-Solving}

Code Number

Problem-solving, or the way we deal with challenges and new situations, is a very important aspect of our everyday lives. This questionnaire is designed to gather information about an individual's problem solving process, in order to better understand social problemsolving.

In this packet, you will read through two different situations. For each, there is a short description, followed by a few questions for you to answer about issues involved in the situation. Then you will be asked to list as many possible solutions you can think of for each situation. The situations presented may or may not have occurred in your own life, so please try to answer all of the questions from the viewpoint of the main character. Remember, there are no right or wrong answers, so answer each question as best as you can.

Thank you for your time and help in completing this questionnaire. If you have any further questions, please contact:

Jennifer Flinn

West Virginia University 
Code Number

Joe and Susan both hold full-time jobs in Philadelphia. They both grew up in the local area, and both their parents live in nearby communities. Joe and Susan also have two children, one in $5^{\text {th }}$ grade and one in $10^{\text {th }}$ grade. Joe's boss (for formtype B: "Susan's boss”) offers him a new position, a promotion from his current place in the company. The job would provide more money and some additional benefits compared to the job position Joe currently holds. The new position, however, is located at an office in Chicago.

Please describe all of the issues that Joe (Susan) must consider in dealing with this problem. 
Code Number

What is the main problem that Joe (Susan)faces?

What is Joe's (Susan)goal in solving this problem? 
Code Number

What should Joe (Susan)do to deal with the problem?

Write down all of the possible ways that Joe (Susan) might deal with this problem. Please place each on a separate line. 
How important is this problem? Circle one:

$\begin{array}{ccccc}1 & 2 & 3 & 4 & 5 \\ \text { Very } & \text { Unimportant } & \text { Neutral } & \text { Important } & \begin{array}{c}\text { Very } \\ \text { Unimportant }\end{array} \\ & & & & \text { Important }\end{array}$

How serious is this problem?

$\begin{array}{ccccc}1 & 2 & 3 & 4 & 5 \\ \text { Very } & \text { Trivial } & \text { Neutral } & \text { Serious } & \text { Very } \\ \text { Trivial } & & & & \text { Serious }\end{array}$

Besides yourself, has someone you know faced a problem similar to the one described?

\section{Circle one: YES NO}

If yes, what was your relationship to that person?

Have you ever faced a problem similar to the one described?

Circle one: YES NO

If yes, how long ago? (check one):

within the last month

within the last 6 months

within the last year

within 2-5 years ago

more than 5 years ago 
Code Number

Rebecca and her husband Michael live in Boston and both hold full-time jobs. Rebecca (for formtype B: Michael) grew up in St. Louis, and Rebecca's widowed mother, Mrs. Clark, still lives in that city. Mrs. Clark has recently suffered a stroke and is having difficulty functioning to the extent that she is no longer able to live independently. Rebecca is an only child and must now decide how best to care for her mother.

Please describe all of the issues that Rebecca (Michael) must consider in dealing with this problem. 
Code Number

What is the main problem that Rebecca (Michael) faces?

What is Rebecca's (Michael's) goal in solving this problem? 
Code Number

What should Rebecca (Michael) do to deal with the problem?

Write down all of the possible ways that Rebecca (Michael) might deal with this problem. Please place each on a separate line. 
How important is this problem? Circle one:

$\begin{array}{ccccc}1 & 2 & 3 & 4 & 5 \\ \text { Very } & \text { Unimportant } & \text { Neutral } & \text { Important } & \begin{array}{c}\text { Very } \\ \text { Unimportant }\end{array} \\ & & & & \text { Important }\end{array}$

How serious is this problem?

$\begin{array}{ccccc}1 & 2 & 3 & 4 & 5 \\ \text { Very } & \text { Trivial } & \text { Neutral } & \text { Serious } & \text { Very } \\ \text { Trivial } & & & & \text { Serious }\end{array}$

Besides yourself, has someone you know faced a problem similar to the one described?

\section{Circle one: YES NO}

If yes, what was your relationship to that person?

Have you ever faced a problem similar to the one described?

Circle one: YES NO

If yes, how long ago? (check one):

within the last month

within the last 6 months

within the last year

within 2-5 years ago

more than 5 years ago 
Code Number

Self-Questionnaire (Bem, 1976)

[Participants were given the Bem Sex Role Inventory to complete.] 


\section{Information about You}

Code Number

Sex: Male Female (Circle one)

Age: __ in years

Date of Birth:

$$
\overline{\text { month }} \overline{\text { day }} \overline{\text { year }}
$$

Race (check one): ___ African American

_ Asian
Caucasian
Hispanic
Biracial (Specify) ___ and

Highest Education: in years

(ex. High school degree $=12$ years; 2 years of college $=14$ years; college degree $=16$ years)

Highest Degree Earned:

What city/town and state are you a permanent resident of? city/town state 
Estimation of current yearly salary:

less than 10,000

$10,000-20,000$

$20,000-30,000$

$30,000-40,000$
$40,000-50,000$
$50,000-60,000$
60,000 or higher

Number of siblings: (living and deceased)

How many of your siblings are male?

How many of your siblings are female?

Number of children: (living and deceased)

How many of your children are male?

How many of your children are female?

Religious Affiliation (check one):

Jewish

Protestant (specify denomination

Catholic

Muslim

Other

(specify

None 
What is your marital status? Are you:

Married (indicate number of years married

Not married, but living together as married (indicate number of years living together

Widowed (indicate number of years married and number of years widowed

Divorced (indicate number of years married and number of years divorced

Never married

Other (specify

Do you currently live:

Alone

With a spouse

With a significant other (boyfriend/girlfriend)

With a friend / not related

With relatives (specify relationship

With others (specify relationship 
For the next four questions, circle the answer that best applies for you:

How would you rate your overall health at the present time:
1) Excellent
2) Good
3) Fair, or
4) Poor?

Is your health now better, about the same, or not as good as it was 3 years ago?
1) Better
2) Same
3) Not as good

Do your health problems stand in the way of your doing the things you want to do?
1) Not at all
2) A little
3) A great deal

Compared with most other people your age, would you say your health is:

1) Better,

2) The Same, or

3) Not as good? 
What kind of work have you done most of your life?

For what kind of business, company or agency is that?

What is your current work status? Are you:

Employed full time

Employed part time

Retired

__Unemployed

Homemaker

Other (specify

What kind of work does/did your mother do?

What kind of work does/did your father do?

What kind of work does/did your spouse do? 
Please indicate which of the following decisions you are currently considering:

Moving to a different home within my town

Moving to a different town within my state

Moving to a different state

Moving my parent to live near me

Moving to live near my parent

How to best care for my parent as she/he ages

I am not currently considering any decisions related to where I live

How long have you lived at your current residence?

years months

Before you moved to your current residence, how many other places have you lived?

(Check one)

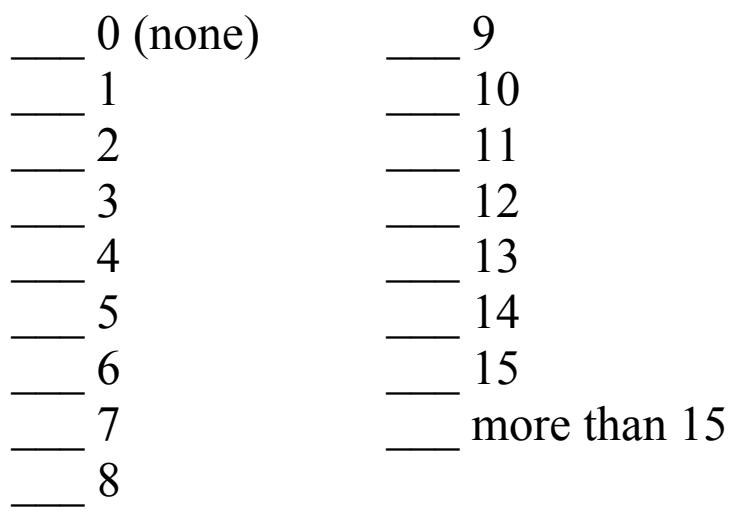


How many places have you lived in the last five years?

How many places have you lived in the last two years?

How many places have you lived in the last year?

What is the longest amount of time you ever lived in one place (the same house of apartment building)?

When you moved to where you live now, what was the reason for your move?

Finally, many people are involved in a variety of relationships. Please indicate (by an X or check-mark) which of the following applies to you. You may indicate more than one:

$\square$ I receive caregiving assistance from a family member (if yes, please specify their relationship to you:

$\square$ I provide caregiving to my spouse.

I provide caregiving to my mother or mother-in-law.

$\square$ I provide caregiving to my father or father-in-law.

I provide caregiving to an adult son or daughter with a disability (if yes, please specify the disability: ).

$\square$ I have minor-aged children of my own living in the household. (list continued on next page) 
$\square$ I have adult sons and/or daughters living in the household.

I am raising a grandchild, niece, or nephew.

$\square$ Other_(Specify:

None of these apply to me

Thank You for your participation! 


\section{Figure Captions}

Figure 1. Model for everyday problem solving (adapted from Sansone \& Berg, 1993).

Figure 2. Mediation model: goals as mediators of problem-solving strategies.

Figure 3. Chart for domain by strategy by sex interaction.

Figure 4. Chart for strategy by age by sex interaction. 


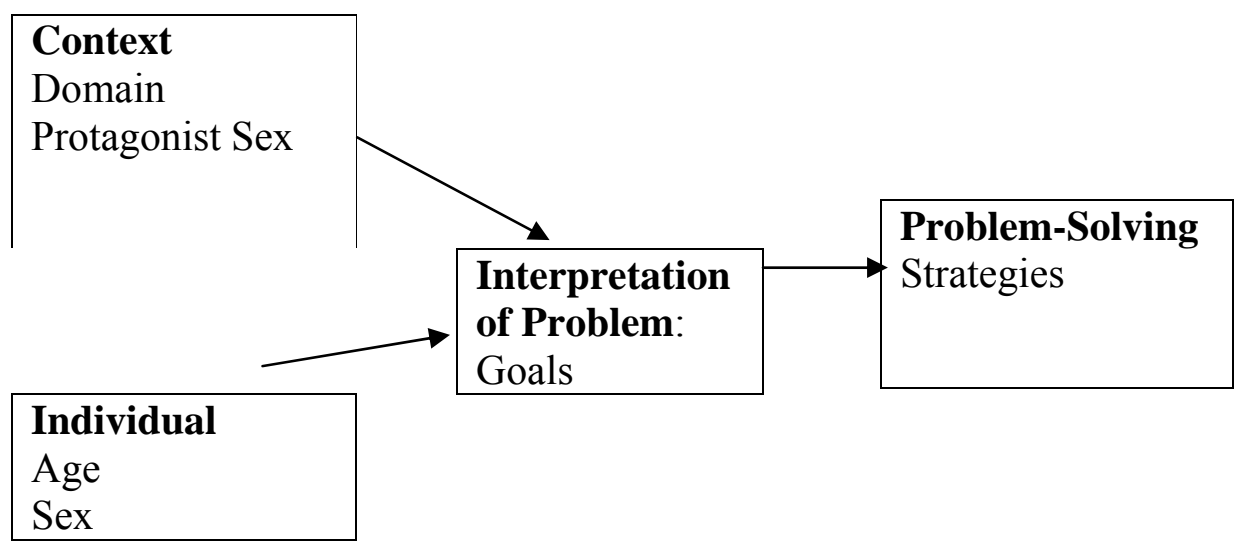




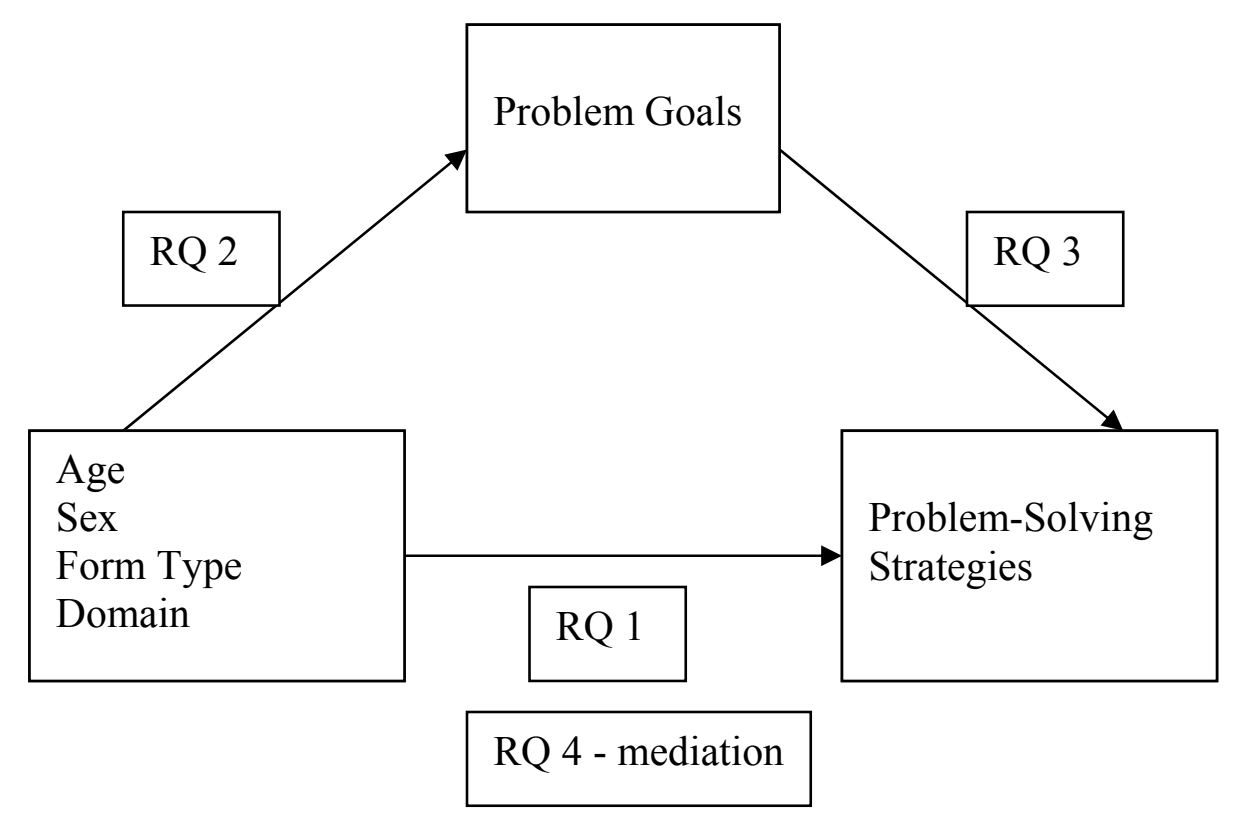


Strategy - Discussion

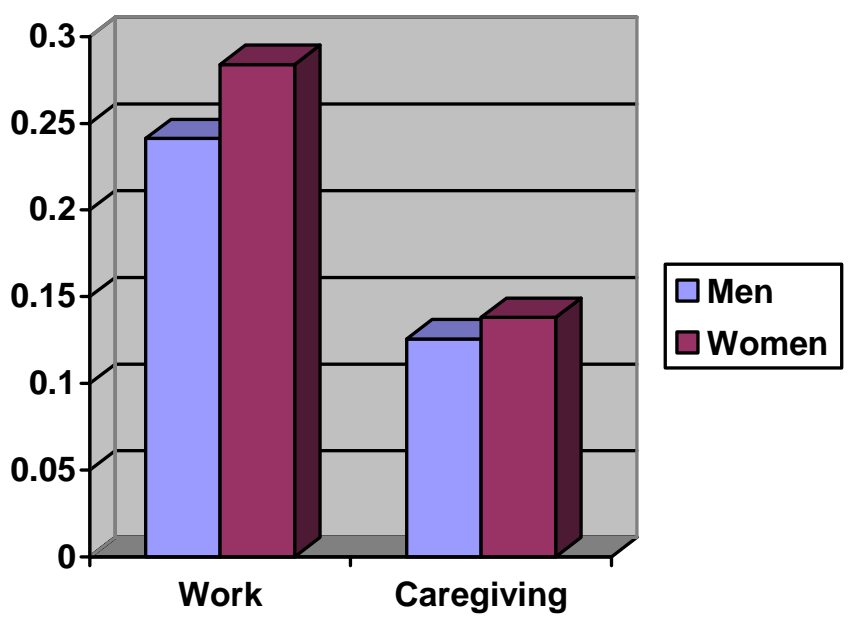

Strategy - Seeking Support

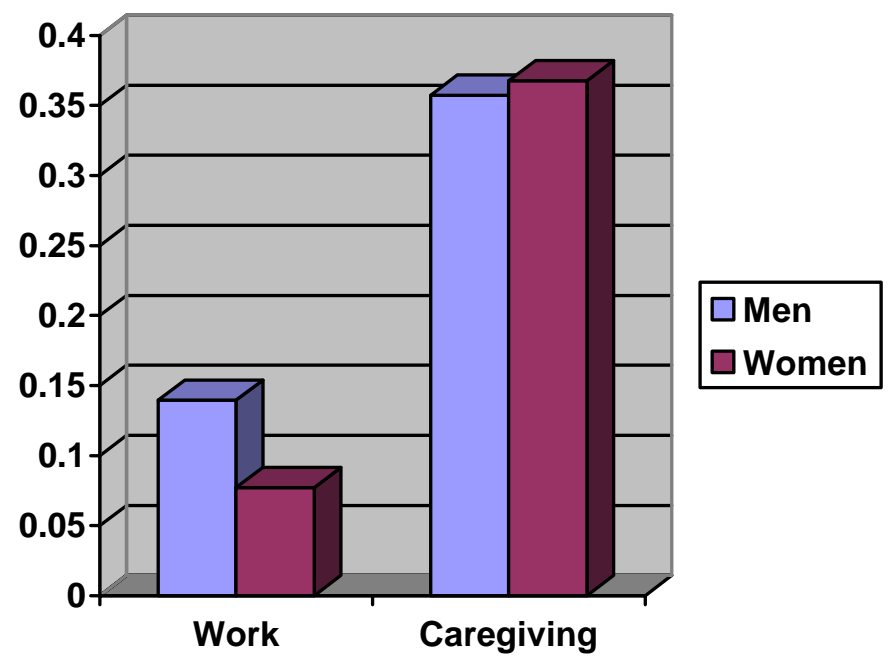


Strategy - Discussion (collapsed)

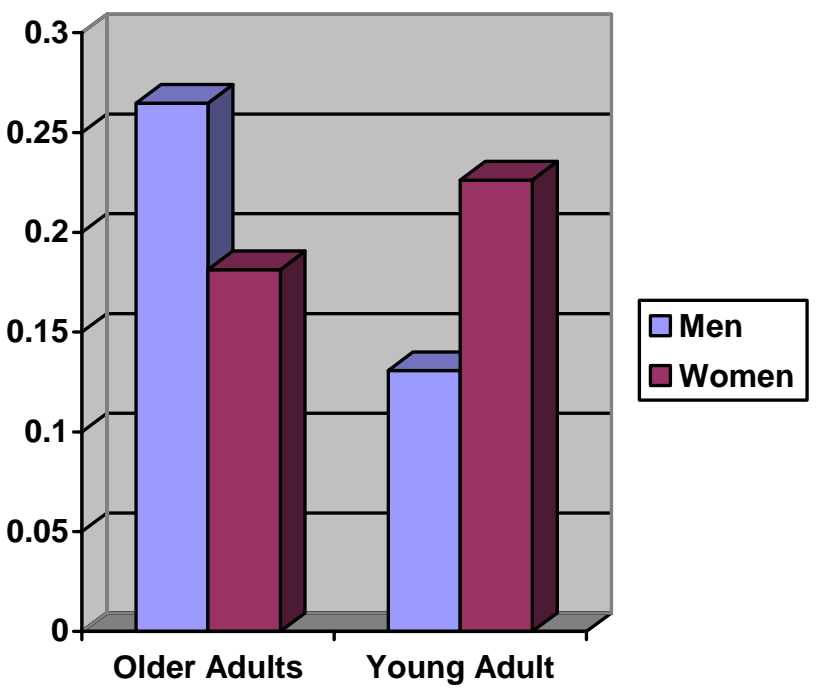

Strategy - Seeking Support (collapsed)

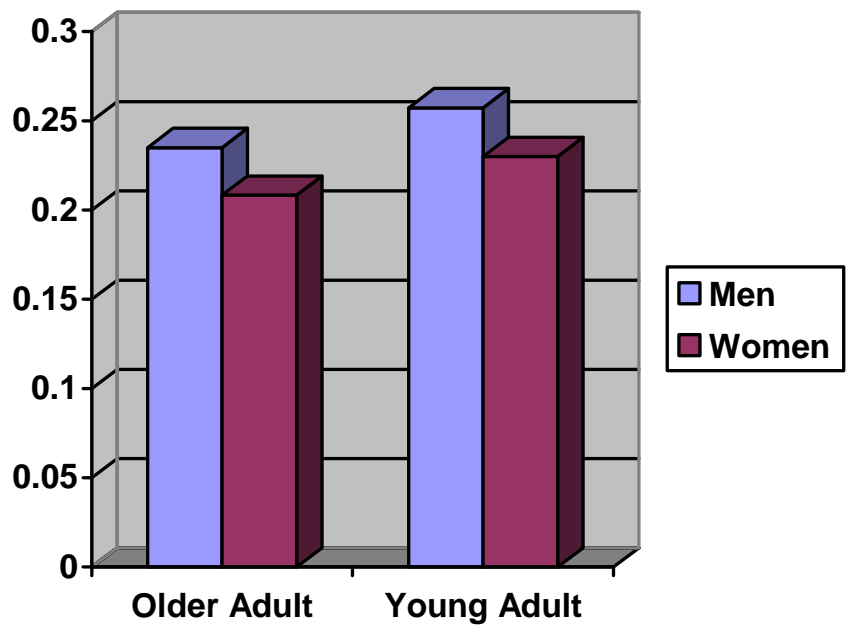


Table 1

Demographic Information: Sex, Race, and Religious Affiliation

\section{Young Adults Older Adults}

Sex

Male

Female

Race

African American

Asian

Caucasian

Hispanic

Biracial

Other

Religious Affiliation
$42.2 \%$

$57.8 \%$

$53.2 \%$
$46.8 \%$

$2.2 \%$

$4.4 \%$

$1.3 \%$

$88.1 \%$

$97.5 \%$

$.7 \%$

$2.2 \%$

$2.2 \%$

$1.3 \%$

$34.1 \%$

$15.2 \%$

Protestant

$27.4 \%$

$70.9 \%$

Jewish

$2.2 \%$

$2.5 \%$

Other

$24.4 \%$

$5.1 \%$

None

$8.9 \%$

$3.8 \%$

Missing

$.7 \% \quad 2.5 \%$


Table 2

Demographic Information: Current Work Status and Any Experience with Caregiving Young Adults Older Adults

Current Work Status

$\begin{array}{lcc}\text { Employed Full Time } & 1.5 \% & 12.7 \% \\ \text { Employed Part Time } & 37.8 \% & 16.5 \% \\ \text { Retired } & .7 \% & 62.0 \% \\ \text { Unemployed } & 45.2 \% & 1.3 \% \\ \text { Homemaker } & - & 7.6 \% \\ \text { Other } & 14.1 \% & - \\ \text { Missing } & .7 \% & -\end{array}$

Caregiving Experience

$\begin{array}{lll}\text { Yes } & 3.0 \% & 15.2 \% \\ \text { No } & 97 \% & 84.8 \%\end{array}$


Table 3

Demographic Information: Education, Income, and Marital Status

$$
\text { Young Adults Older Adults \% of Total }
$$

Education

Less than high school

High School

Associates

Bachelors

Masters

$\mathrm{PhD}$

Income

Below $\$ 10,000$

$\$ 10,000-39,999$

$\$ 40,00-59,999$

Above $\$ 60,000$

Marital Status

Married

Not married, living

together

Widowed

Divorced

Never married

Other
$.7 \%$

$2.2 \%$

$23.5 \%$

$6.2 \%$

$91.9 \%$

$5.1 \%$

$1.2 \%$

$.5 \%$

$97.8 \%$

$29.6 \%$

$72.4 \%$

$.7 \%$

$3.7 \%$

$2.4 \%$

$29.6 \%$

$11.2 \%$

$14.8 \%$

$5.6 \%$

$6.2 \%$

$2.3 \%$

$80.9 \%$

$6.2 \%$

$52.3 \%$

$7.3 \%$

$39.5 \%$

$19.1 \%$

$3.7 \%$

$14.8 \%$

$7.5 \%$

$6.6 \%$

$18.5 \%$

$11.2 \%$ 
Table 4

Distribution of Form Type for Returned Questionnaires by Age and Sex

\begin{tabular}{llccc}
\hline Age & Protagonist Sex & Sex of & Participant & Total \\
\hline & & Male & Female & \\
\hline Young adults & Male Protagonist & 30 & 33 & 63 \\
& Female Protagonist & 27 & 45 & 72 \\
& Total & 57 & 78 & 43 \\
Older adults & Male Protagonist & 19 & 22 & 38 \\
& Female Protagonist & 18 & 20 & 79
\end{tabular}

Note. Medium power required at least 17 participants per cell. 
Table 5

Analysis of Variance Results for Seeking Support Strategy by Domain by Sex

\begin{tabular}{|c|c|c|c|c|}
\hline Variables & $\underline{\mathrm{df}}$ & $\underline{\mathrm{MS}}$ & $\underline{F}$ & $\underline{\text { Partial } \eta^{2}}$ \\
\hline Sex & 1 & .207 & $9.206^{*}$ & .003 \\
\hline Error & 212 & 0.02243 & & \\
\hline
\end{tabular}


Table 6

Means and Standard Deviations for Seeking Support Proportion Scores for the Work Problem by Age

\begin{tabular}{lcc}
\hline Sex & Mean & Std. Deviation \\
\hline Male & $.1396^{*}$ & .1825 \\
Female & .0771 & .1181 \\
Total & .1046 & .1526 \\
\hline$* \mathrm{p}<.05$. & & \\
\hline
\end{tabular}


Table 7

Analysis of Variance Results for Main Effects and Interaction Effects of Age and Sex on Collapsed Discussion Proportion Scores

\begin{tabular}{lcccc}
\hline \multicolumn{1}{c}{ Variables } & $\underline{\mathrm{df}}$ & $\underline{\mathrm{MS}}$ & $\underline{\mathrm{F}}$ & $\underline{{\text { Partial } \eta^{2}}^{2}}$ \\
\hline Age & 1 & .101 & 3.047 & .014 \\
Sex & 1 & .00224 & .068 & .000 \\
Age $\mathrm{x}$ Sex & 1 & .388 & $11.70^{*}$ & .053 \\
Error & 210 & .03313 & & \\
\hline$* \mathrm{p}<.05$. & & & &
\end{tabular}


Table 8

Means and Standard Deviations for Collapsed Discussion Proportion Scores by Age and Sex

\begin{tabular}{cccc}
\hline Age & Sex & Mean & Std. Deviation \\
\hline Young Adult & Male & .1307 & .1602 \\
& Female & .2262 & .2021 \\
& Total & .1859 & .1909 \\
Older Adult & Male & $.2647^{*}$ & .1998 \\
& Female & .1828 & .1513 \\
& Total & .2211 & .1793 \\
Total & Male & .1835 & .1877 \\
& Female & .2110 & .1864 \\
& Total & .1989 & .1870
\end{tabular}

$* \mathrm{p}<.05$. 
Table 9

Correlations Between Other- and Self-Focused Goals and Interpersonal and Instrumental Strategies

\begin{tabular}{|c|c|c|c|c|c|c|c|c|c|c|c|c|}
\hline & 1 & 2 & 3 & 4 & 5 & 6 & 7 & 8 & 9 & 10 & 11 & 12 \\
\hline 1 - Self-focused goals - Work & - & & & & & & & & & & & \\
\hline 2 - Other-focused goals - Work & -.015 & - & & & & & & & & & & \\
\hline 3 - Self-focused goals - Caregiving & -.006 & .067 & - & & & & & & & & & \\
\hline 4 - Other-focused goals - Caregiving & -.055 & .068 & -.052 & - & & & & & & & & \\
\hline 5 - Deliberation strategy - Work & -.074 & -.002 & .065 & $-.169 *$ & - & & & & & & & \\
\hline 6 - Self-action strategy - Work & -.023 & .010 & .079 & .128 & $-.479 * *$ & - & & & & & & \\
\hline 7 - Discussion strategy - Work & .024 & -.018 & -.020 & -.077 & -.116 & $-.527 * *$ & - & & & & & \\
\hline 8 - Seeking Support strategy - Work & .078 & .075 & -.037 & .012 & $-.197 * *$ & $-.254 * *$ & .043 & - & & & & \\
\hline 9 - Deliberation strategy - Caregiving & .076 & -.021 & .088 & $-.155^{*}$ & $.276^{* *}$ & $-.200 * *$ & .108 & .000 & - & & & \\
\hline 10 - Self-action strategy - Caregiving & -.087 & -.004 & -.035 & .091 & -.129 & $.209 * *$ & $-.266 * *$ & -.045 & $-.449 * *$ & - & & \\
\hline 11 - Discussion strategy - Caregiving & .088 & -.008 & -.022 & .098 & .072 & $-.281 * *$ & $.335 * *$ & .094 & $.172 *$ & $-.530 * *$ & - & \\
\hline 12 - Seeking Support strategy - Caregiving & -.057 & -.048 & .062 & -.065 & -.068 & $.145^{*}$ & -.073 & -.023 & $-.473 * *$ & -.078 & $-.435 * *$ & - \\
\hline
\end{tabular}

